\title{
Tunnel Misalignment with Geostatic Principal Stress Directions in Anisotropic Rock Masses
}

\author{
O.P.M. Vitali, T.B. Celestino, A. Bobet
}

\begin{abstract}
Rock masses may present pronounced stress anisotropy, and so it is likely that a tunnel is misaligned with the geostatic principal stress directions. As a consequence, anti-symmetric axial displacements and axial shear stresses are induced around the tunnel due to the presence of far-field axial shear stresses. Limited research has been conducted on the effects of-far-field axial shear stresses on tunnel behavior. This paper investigates the effects of tunnel misalignment with the geostatic principal stresses in anisotropic rock masses. 3D FEM modeling of a tunnel misaligned $45^{\circ}$ with the principal horizontal stresses is conducted. An anisotropic geostatic stress field is considered, with the major horizontal stress two times larger than the vertical stress and the minor horizontal stress equal to the vertical stress. The anisotropic behavior of the rock mass is represented by a transversely anisotropic elastic model, with properties typical of anisotropic rock masses. Tunnels in horizontally and vertically-structured rock masses are assessed. Unsupported and supported tunnels are investigated. The results show that asymmetric deformations and asymmetric stresses are induced near the face of the tunnel as a result of the tunnel misalignment with the geostatic principal stresses and with the rock mass structure. These asymmetric deformations near the face affect the ground-support interaction such that the internal forces in the liner are also asymmetric.
\end{abstract}

Keywords: 3D face effects, anisotropy, far-field shear stress, geostatic stress anisotropy, rock anisotropy, tunnel, tunnel misalignment.

\section{Introduction}

The literature shows that rock masses are likely to present pronounced geostatic stress anisotropy and anisotropic mechanical properties. This is a consequence of the rock complex formation processes. According to Brady \& Brown (2006), the main factors affecting rock mass properties and geostatic stresses are: topography (elevations and valleys); residual stresses (due to cooling, for instance); tectonic movements; fracturing and jointing; and inclusions. Thus, geostatic stresses and mechanical properties are expected to be complex as well. In-situ stress measurements in rock masses show large horizontal stresses and significant horizontal stress anisotropy (Gysel, 1975; Brown \& Hoek, 1978; McGarr \& Gay, 1978; Evans et al., 1989; Martin, 1997; Haimson et al., 2003; Wileveau et al., 2007; Zhao et al., 2013, 2015; Park et al., 2014; Perras et al., 2015; Soucek et al., 2017). For instance, Martin (1997) reported a highly anisotropic stress field in a massive granitic rock mass in Canada. The average stresses were: $\sigma_{1} / \sigma_{2}=1.2 \pm 0.1$ and $\sigma_{1} / \sigma_{3}=3.9 \pm 0.5$. Gysel (1975) presented the geostatic stress field measured in two sections along the Sonnerberg tunnel (Lucerne, Switzerland), in sandstone. The stress ratios were $\sigma_{1} / \sigma_{3}=2.33, \sigma_{1} / \sigma_{2}=2.10$ on one of the sections and $\sigma_{1} / \sigma_{3}=4.29$, and $\sigma_{1} / \sigma_{2}=1.70$ on the other. Haimson et al. (2003) and Park et al. (2014) eval- uated the geostatic stress field of granitic and gneissic rock masses in South Korea, near Seoul, in an active seismic area. The measured horizontal stresses showed large stress anisotropy and were consistently larger than the vertical stress. An extensive compilation of 77 geostatic stresses was conducted by McGarr \& Gay (1978), where the interval, with $95 \%$ confidence, for each principal stress ratio was: $\sigma_{1} / \sigma_{2}=1.45 \pm 0.80$ and $\sigma_{1} / \sigma_{3}=2.42 \pm 2.28$. These data show that the expected stress anisotropy in rock is indeed high and quite variable.

The importance of tunnel alignment with the geostatic principal stress directions is recognized in the literature. Goodman (1989) recommends aligning the tunnel or cavern with the major principal stress to minimize stress concentrations around the opening. Convergence measurements of tunnels constructed in the Underground Research Laboratory (URL) in France showed the importance of the tunnel orientation with respect to the geostatic principal stress directions. These tunnels were excavated in an anisotropic claystone rock mass at $490 \mathrm{~m}$ depth, with average principal stress ratios $\sigma_{h} / \sigma_{v}=1$ and $\sigma_{H} / \sigma_{v}=1.3$ (Wileveau et al., 2007). Because of the sedimentation process, the rock had an oriented structure (horizontal bedding), and thus anisotropic mechanical properties, with $E_{1} / E_{3}$ varying from 1.2 to 2 (Armand et al., 2013). Experimental tunnels were

Osvaldo Paiva Magalhães Vitali, MSc, Ph.D. Candidate, Lyles School of Civil Engineering, Purdue University, West Lafayette, IN, USA. e-mail: ovitali@ purdue.edu. Tarcisio Barreto Celestino, Ph.D., Professor Doctor, São Carlos School of Engineering, University of São Paulo, São Carlos, SP, Brazil. e-mail: tbcelest@ usp.br. Antonio Bobet, Ph.D., Edgar B. and Hedwig M. Olson Professor, Lyles School of Civil Engineering, Purdue University, West Lafayette, IN, USA. e-mail: bobet@ecn.purdue.edu.

Submitted on September 28, 2019; Final Acceptance on February 13, 2020; Discussion open until August 31, 2020 DOI: $10.28927 /$ SR.431123 
excavated parallel and perpendicular to $\sigma_{H}$. A supported circular tunnel of radius $2.6 \mathrm{~m}$, aligned with $\sigma_{H}$, showed horizontal convergence of 37 to $58 \mathrm{~mm}$ and vertical convergence of 24 to $30 \mathrm{~mm}$. A similar tunnel aligned with $\sigma_{h}$ showed horizontal convergence of $19 \mathrm{~mm}$ to $34 \mathrm{~mm}$ and vertical convergence of $112 \mathrm{~mm}$ to $158 \mathrm{~mm}$ (Armand et al., 2013).

Tunnel design is commonly conducted assuming that the tunnel is aligned with one of the geostatic principal stress directions and yet, as previously discussed, the assumption is unrealistic. When the tunnel is misaligned with the geostatic principal stress directions, far-field axial shear stresses are present. These axial shear stresses induce antisymmetric axial displacements and axial shear stresses farbehind the tunnel face (Vitali et al., 2018; 2019a; 2019b; $2019 \mathrm{c}$ ). On shallow tunnels in isotropic ground, Vitali et al. (2019b) observed that the far-field axial shear stress induced asymmetric deformations and stresses near the face and that ground-support interaction and yielding around the tunnel, if any, were affected by the asymmetric deformations near the face. Vitali et al. (2019c) investigated the effects of tunnel misalignment on the progressive failure around the well-documented experimental tunnel at the URL in Canada (Martin, 1997). They found that no plastic deformations at the tunnel walls occurred when the tunnel was aligned with the minor principal stress, but asymmetric spalling would occur if the tunnel was not aligned with the geostatic principal stresses.

Asymmetric deformations of the tunnel walls have been observed on tunnels in structured rock masses, such as phyllites and slates. For instance, asymmetric radial displacements at the tunnel wall, horizontal displacements at the crown and axial displacements at the springline are often measured on the shotcrete support of NATM tunnels in anisotropic rock masses (Schubert \& Budil, 1995; Goricki et al., 2005; Schubert et al., 2005; Schubert \& Moritz, 2011; Klopcic \& Logar, 2014; Lenz et al., 2017). Those asymmetric deformations are commonly associated with the anisotropic properties of the rock mass and with localized heterogeneities. Button et al. (2006) observed that the asymmetric deformation patterns observed in the field could be partially reproduced numerically in tunnels not aligned with the rock mass structure. Tonon and Amadei, (2002, 2003) and Fortsakis et al. (2012) highlighted the importance of considering the anisotropic properties of the rock mass in numerical models to obtain more accurate ground deformation predictions (they assumed, however, that the tunnel was aligned with the geostatic principal stresses). In this paper, the influence of the tunnel misalignment with the geostatic principal stresses in anisotropic rock masses is assessed, for unsupported and supported tunnels, through 3D FEM modeling. Horizontally- and vertically-structured rock masses are considered. A transversely anisotropic elastic model is adopted to represent the rock mass.

\subsection{FEM Model}

3D FEM modeling was conducted to investigate tunnels misaligned with the geostatic principal stresses in anisotropic rock masses. A tunnel misaligned $45^{\circ}$ with the major principal horizontal stress, in a transversely anisotropic rock mass, is assumed. The rock mass is assumed elastic with the following properties: Young modulus perpendicular to the structural planes $\left(E_{1}\right), 1 \mathrm{GPa}$; Young modulus parallel to the structural planes $\left(E_{2}=E_{3}\right), 3 \mathrm{GPa}$; in-plane Poisson ratio $\left(v_{23}\right), 0.333$; out-of-plane Poisson ratio $\left(v_{13}=v_{12}\right), 0.25$; in-plane Shear modulus $\left(G_{23}\right)$, $1.125 \mathrm{GPa}$; and out-of-plane Shear modulus $\left(G_{23}=G_{13}\right)$, $0.667 \mathrm{GPa}$. These properties are typical of highly anisotropic rock masses, such as phyllites and slates. According to Worotnicki (1993), more than $50 \%$ of highly structured rock masses present a $\mathrm{E}_{1} / \mathrm{E}_{2}$ ratio larger than 2 . For the simulations, horizontal and vertical structural planes are considered (i.e. dip angles $0^{\circ}$ and $90^{\circ}$, respectively). The geostatic principal stresses are: vertical stress $\left(\sigma_{v}\right), 5 \mathrm{MPa}$ (the vertical stress is assumed as a principal stress), minor horizontal stress $\left(\sigma_{h}\right), 5 \mathrm{MPa}$ and major horizontal stress $\left(\sigma_{H}\right)$, $10 \mathrm{MPa}$. This is not an unusual anisotropic stress field, according to e.g. Gysel, 1975; Evans et al., 1989; Haimson et al., 2003; Wileveau et al., 2007; Park et al., 2014; Soucek et al., 2017. Two directions for the major horizontal stress are evaluated: $\sigma_{H}$ perpendicular to the strike and $\sigma_{H}$ parallel to the strike of the rock structure (i.e. perpendicular or parallel to the rock bedding; note that the direction of the horizontal stresses for a tunnel parallel to the rock structure does not change the results due to the symmetry of the problem).

Figure 1 shows the FEM mesh built for the investigation. The tunnel is circular with radius $\left(\mathrm{r}_{0}\right) 5 \mathrm{~m} .2^{\text {nd }}$ order hexahedron elements are used. The mesh refinement and the size of the model (Fig. 1a) are selected to ensure the results accuracy, following the recommendations provided by Vitali et al. (2017). Figure 1b illustrates the plan view of the mesh with the boundary conditions, where $\Psi=45^{\circ}$ is the angle that the tunnel makes with the principal horizontal stresses. The geostatic stress field is generated by applying a load pressure at the boundaries with the same magnitude as the geostatic principal stresses. Given the anisotropic rock masses investigated (i.e. horizontally- and verticallystructured rock masses) and that the vertical axis is a principal stress direction, it is possible to take advantage of the symmetry of the problem and use only half the discretization. The mesh consists of a refined structured grid at the center of the model, where the results are extracted, linked to the boundaries by an unstructured grid, as shown in Figs. 1c and 1d.

Supported and unsupported tunnels are considered. The 3D FEM simulation follows the excavation sequence of the tunnel by deactivating the elements inside the excavation and activating the elements that represent the tunnel 
support, if present. The simulations are run in two steps: the first step generates the geostatic stress field, and the second, the excavation and support, if present. The liner is represented by shell elements with thickness $0.5 \mathrm{~m}\left(0.1 \mathrm{r}_{0}\right)$. No slip between ground and liner is allowed. Figure 2 illustrates the mesh near the face of a supported tunnel. The liner, if included, is installed immediately after the excavation; that is, the unsupported span is zero. In Fig. 2, position 1 indicates a location far-ahead of the face of the tunnel and represents the region not affected by the tunnel excavation; position 2 is at the face of the tunnel; and position 3, far-behind the face of the tunnel, where stresses and displacements are independent of the distance from the face of the tunnel.

\section{Tunnel in Horizontally Structured Rock Mass}

Horizontal stratification is not uncommon in sedimentary and even metamorphic rock masses. The effects of such structure on tunnels misaligned with the geostatic principal stresses are analyzed through a number of simulations where the tunnel is horizontal and, thus, aligned with the rock mass structure. Two cases are studied: (1) far-field stresses $\sigma_{x x, f f}=\sigma_{z z \text { zff }}=7.5 \mathrm{MPa}, \sigma_{v y, f f}=5 \mathrm{MPa}, \tau_{x z \text { zff }}=2.5 \mathrm{MPa}$ (tunnel oriented at $\Psi=45^{\circ}$ with the far-field principal stresses) and (2) same far-field stresses, but no far-field shear, i.e. $\sigma_{x x, f f}=\sigma_{z x f f}=7.5 \mathrm{MPa}, \sigma_{y, f f}=5 \mathrm{MPa}, \tau_{x z \text { fff }}=0$, to investigate the influence of the far-field axial shear. (a)

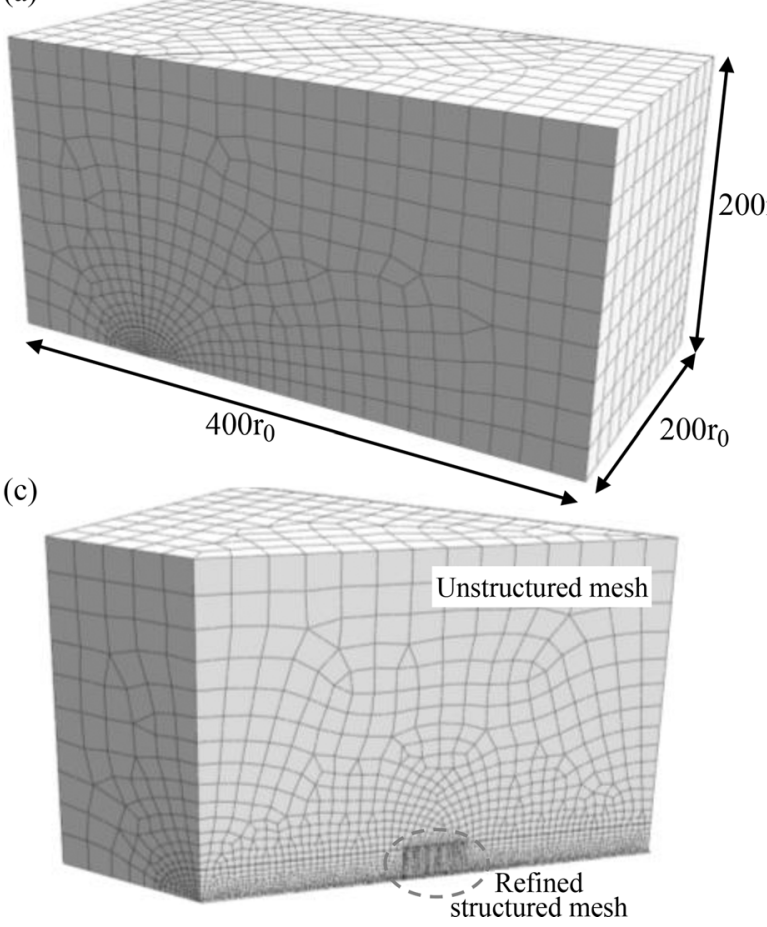

(b)

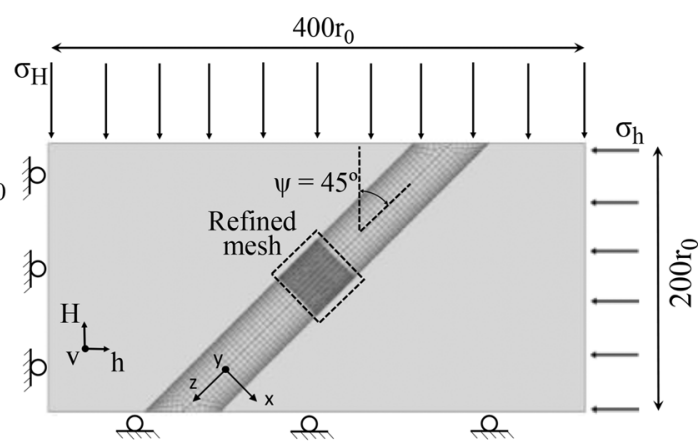

(d)

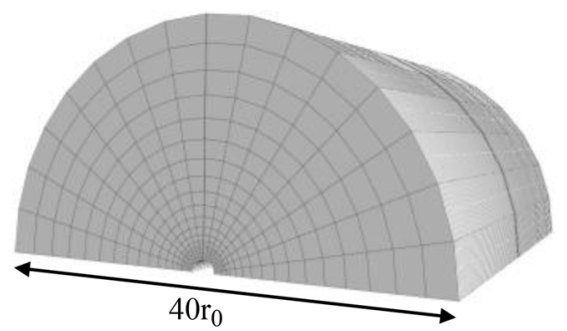

Figure 1 - FEM mesh. (a) Model dimensions; (b) plan view and boundary conditions; (c) vertical cross section along the tunnel and; (d) refined mesh at the center of the model. $\mathrm{r}_{0}$ is the tunnel radius and is $5 \mathrm{~m}$.

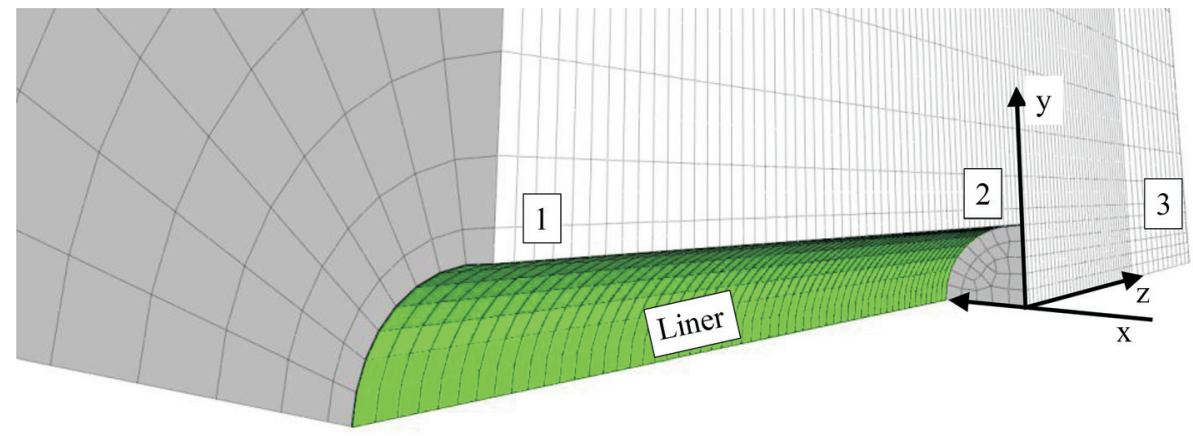

Figure 2 - Mesh near the face of the supported tunnel, with the coordinate system XYZ attached to the tunnel. Position (1) represents a point far ahead of the face; (2), at the face (i.e. $\mathrm{Z}=0$ ); and (3), far-behind the face. 
Figure 3 shows the horizontal and vertical tunnel convergence, normalized with the tunnel radius, with the distance from the face, normalized also with the tunnel radius, for the two cases. Displacements start to increase at $4 \mathrm{r}_{0}$ ahead of the face, abruptly increase at the face and increase further behind the face until they are constant at about $4 r_{0}$ behind the face. Tunnel deformations are identical in both cases, which indicates that the far-field axial shear stress has no influence on the results. It is interesting to note that the vertical and the horizontal tunnel deformations are similar, despite the fact that the far-field horizontal stress is

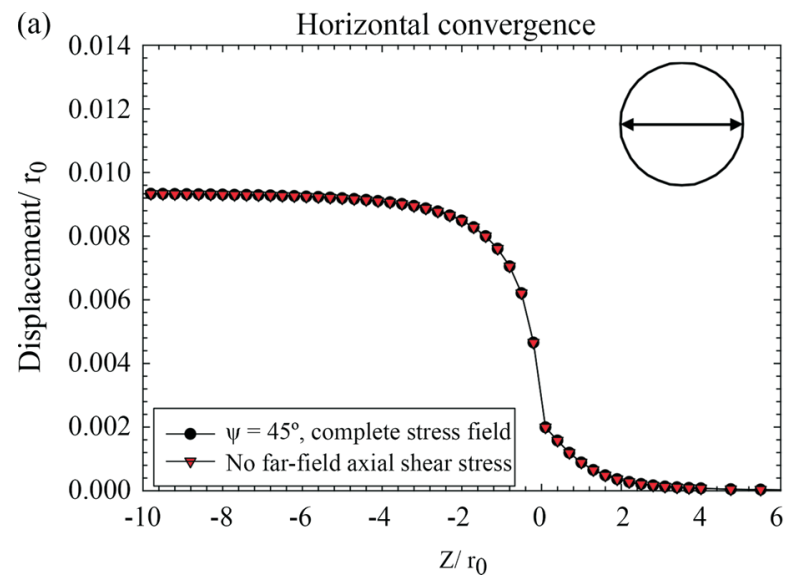

larger than the vertical. The reason for this is that the stiffness of the ground parallel to the rock mass structure is the largest and the stiffness perpendicular to the structure is the smallest. So, in the simulations, the (larger) horizontal stress is parallel to the stiffest rock mass direction and the (smaller) vertical stress is parallel to the softest rock mass direction, and so the two effects compensate each other.

Figure 4 shows the normalized radial displacements and the deformed cross-section at the face and far behind the face. For Case 2, with no far-field axial shear stress, the deformations are symmetric at the face and far-behind the

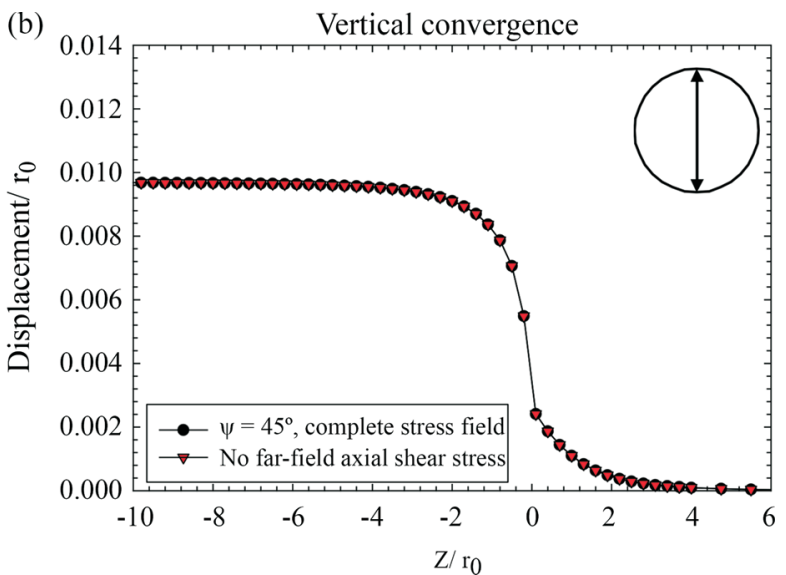

Figure 3 - Tunnel convergence $v s$. distance from the face (both normalized with respect to the tunnel radius) for unsupported tunnel. (a) horizontal convergence, (b) vertical convergence. $\mathrm{Z}$ is the distance from the face of the tunnel (Fig. 2); $\mathrm{r}_{0}$, the tunnel radius, is $5 \mathrm{~m}$. The circles represent the tunnel cross section and the arrows indicate the direction and location of the displacements plotted.
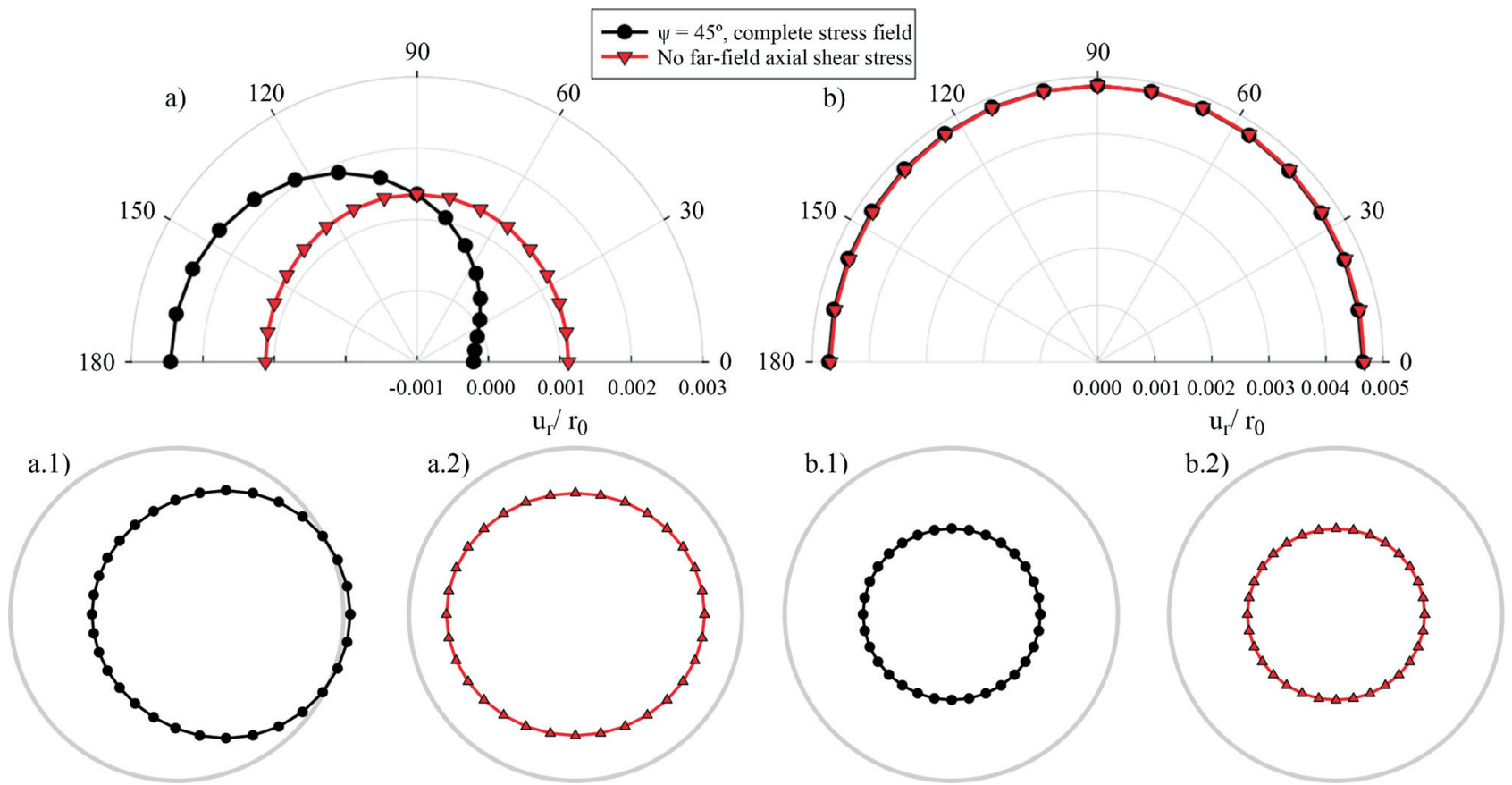

Figure 4 - Normalized radial displacemets at the tunnel perimeter with respect to the tunnel radius and deformed tunnel cross-section, for unsupported tunnel. (a) at the face; (b) far-behind the face. Deformations are magnified 200 times at the face and 100 times far-behind the face. $\mathrm{u}_{\mathrm{r}}$ is the radial dsplacement and $\mathrm{r}_{0}$, the tunnel radius, is $5 \mathrm{~m}$. 

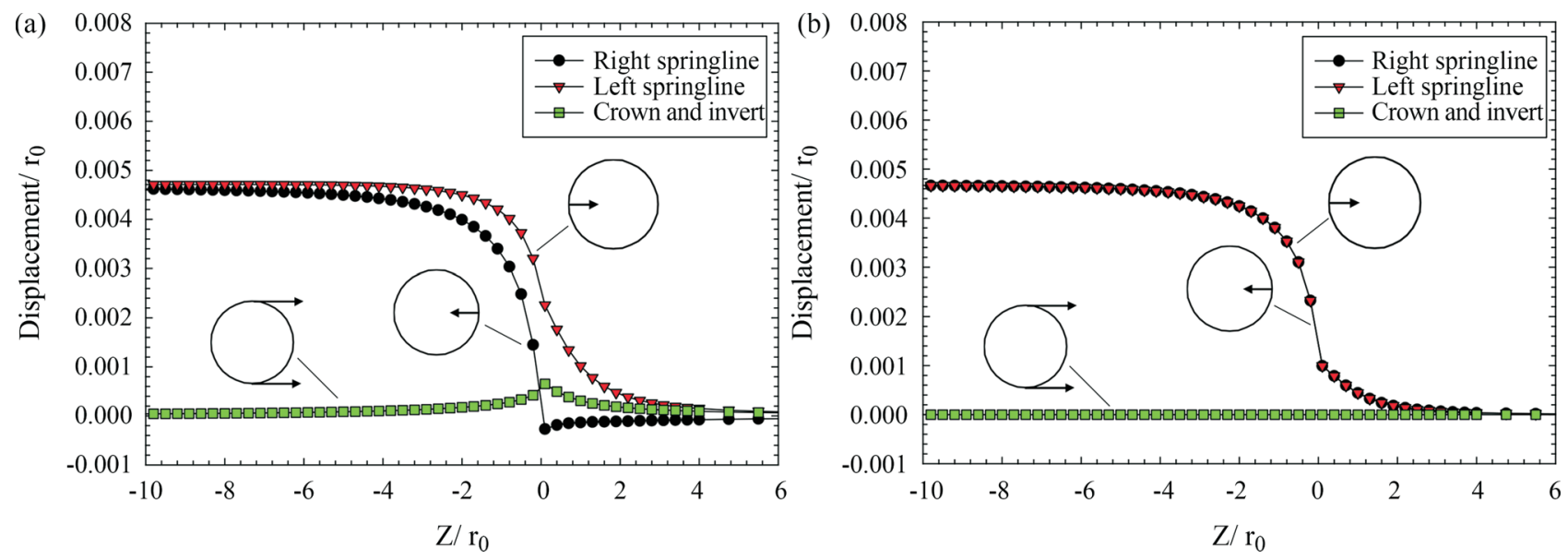

Figure 5 - Displacements $v s$. distance from the face (both normalized with respect to the tunnel radius). (a) Case 1, complete stress field; (b) Case 2, no far-field axial shear. $\mathrm{Z}$ is the distance from the face (Fig. 2); $\mathrm{r}_{0}$ the tunnel radius, is $5 \mathrm{~m}$. The circles represent the tunnel cross section and the arrows indicate the direction and location of the displacements plotted.

face. For Case 1, with the complete stress field, the deformations at the tunnel perimeter are symmetric far-behind the face, but asymmetric at the face, where the tunnel cross section translates towards the right. Far-behind the face, the deformed cross section in both cases is exactly the same, which shows that the far-field axial shear stress does not affect the radial displacements far-behind the face. This is because, when the tunnel axis is aligned with one of the principal material directions, in-plane and out-of-plane deformations are decoupled (Vitali et al., 2020).

The normalized radial displacements at the springline, on the right and left, and the tunnel cross section translation are presented in Fig. 5. For Case 1, complete stress field, the radial displacements are asymmetric from a distance of $4 r_{0}$ ahead of the face to about $6 r_{0}$ behind the face. A translation of the tunnel cross section occurs near the face, which is maximum at the face (i.e. at $\mathrm{Z}=0$ ). For Case 2, the radial displacements at the springline do not change with the distance from the face; that is, no translation of the tunnel cross section occurs. Thus, the presence of the far-field axial shear stress induces asymmetric deformations near the face. Figure 6 shows the normalized "corrected" radial displacements with the normalized distance from the face, for Case 1. The corrected radial displacement is the radial displacement without the translation of the tunnel cross section, as indicated in Fig. 6. The corrected radial displacements are asymmetric near the face, which is consistent with Vitali et al. (2019b). The authors observed that the far-field axial shear stress caused asymmetric radial deformation near the face of a shallow tunnel in isotropic ground. Those asymmetric radial displacements could be decomposed into a rigid body displacement of the tunnel cross section and anti-symmetric radial displacements.

The stress paths, normalized with respect to the vertical stress, at points near the tunnel perimeter (i.e. at right and left springline and at the crown) are shown in Fig. 7

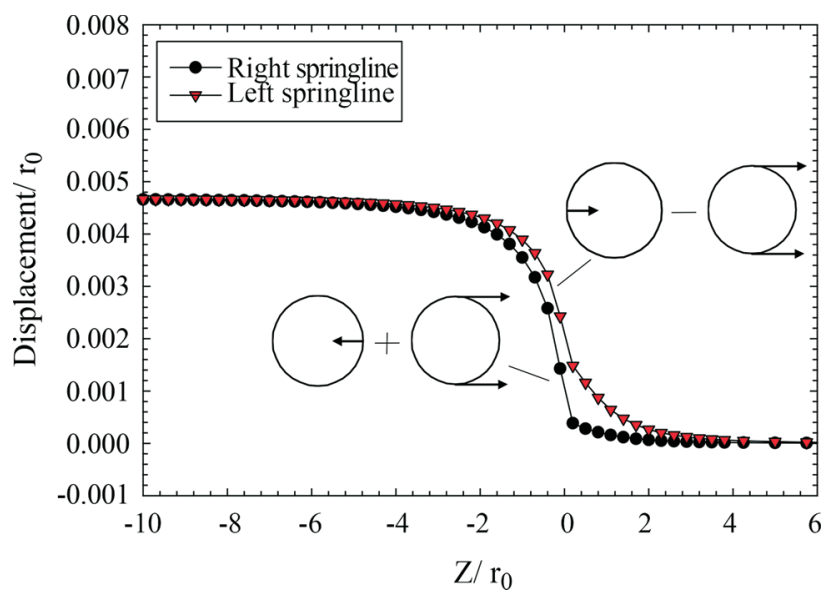

Figure 6 - Displacements $v s$. distance from the face (both normalized with respect to the tunnel radius). Case 1 , complete stress field. $\mathrm{Z}$ is the distance from the face (Fig. 2); $\mathrm{r}_{0}$, the tunnel radius, and is $5 \mathrm{~m}$. The circles represent the tunnel cross section and the arrows indicate the direction and location of the displacements plotted.

(see Fig. 2 for location of points 1, 2, 3). The stresses were computed at a distance of $0.1 \mathrm{r}_{0}$ from the tunnel perimeter, to minimize the disturbance due to the corner between face and tunnel. For Case 1 (complete stress field), on the right-hand side of the springline, the rock stresses increase towards the face of the tunnel, i.e. both mean stress and maximum shear stress increase; close to the face, the stresses abruptly increase, while they steadily decrease behind the face until they reach a constant value. On the left-hand side, the opposite is observed; that is, unloading ahead of the face and loading behind the face. Note that far behind the face of the tunnel, the two stress paths yield the same results. The asymmetry of the stress paths is consistent with the asymmetric deformations near the face discussed previously. Indeed, there is a horizontal translation 

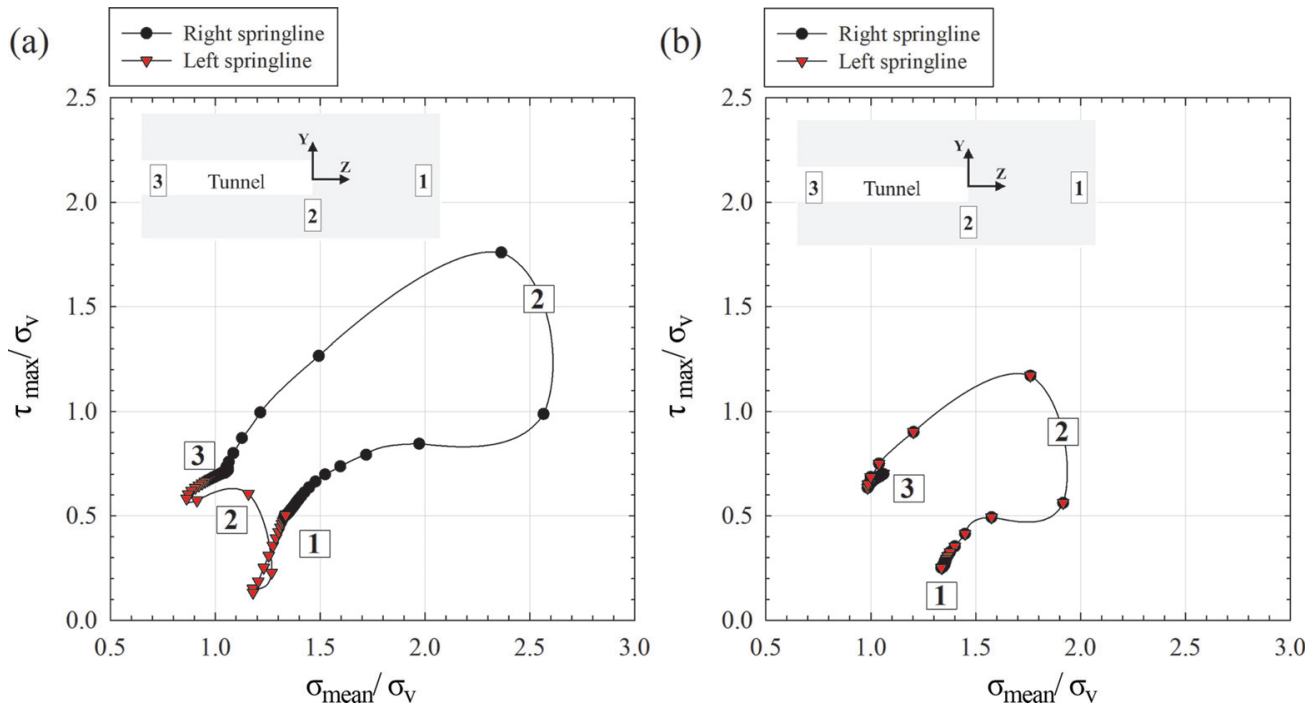

Figure 7 - Normalized stress paths with respect to the vertical stress. (a) Case 1, full stress field; (b) Case 2, no far-field axial shear. Position (1) represents a point far ahead of the face of the tunnel; (2), at the face (i.e. $\mathrm{Z}=0$ ); and (3), far-behind the face.

of the tunnel cross section towards the right near the face, as shown in Fig. 4, that results in compression of the rock at the right springline, while the rock at the left springline is unloaded. For Case 2, no far-field axial shear stress, the two stress paths are exactly the same. There is loading ahead of the face and unloading behind the face. Note that unloading ahead of the face was observed only when the far-field axial shear stress was present. Figure 8 presents the normalized stress paths at the crown for Case 1 (complete stress field) and Case 2 (no far-field axial shear). The stresses at the crown and at the invert are the same because of the symmetry of the problem. The stress paths for the two cases follow a loading path ahead and behind the tunnel face, with an increase of the mean effective stress near the face. The shear

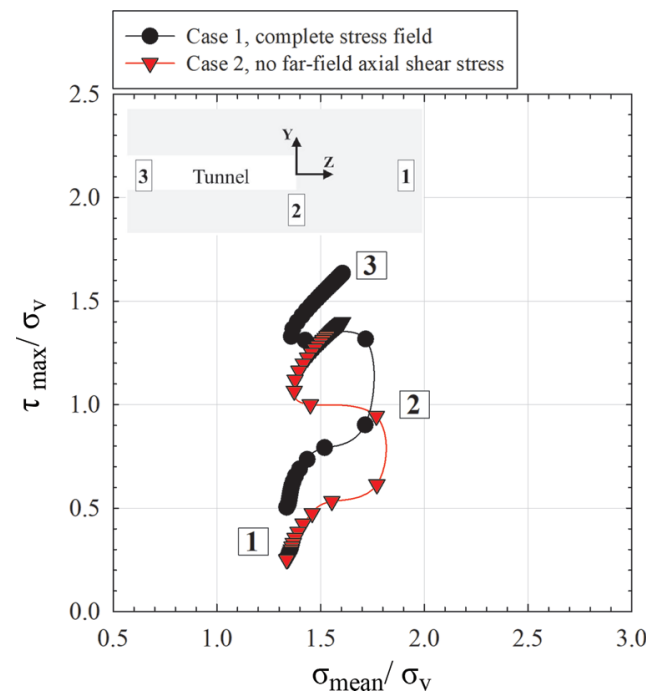

Figure 8 - Stress paths at the crown. Position (1) represents a point far ahead of the face of the tunnel; (2), at the face (i.e. $\mathrm{Z}=0)$; and (3), far-behind the face. stresses are larger for Case 1 than for Case 2 because of the presence of the far-field axial shear stress.

Figure 9 shows the normalized axial displacements at the tunnel perimeter, for Case 1 (complete stress field; for Case 2, no axial displacements were induced far-behind the face). As one can see in the figure, anti-symmetric axial displacements are induced far-behind the face. The axial displacements are maximum at the springline and zero at the crown; those are produced by the far-field axial shear stress. At the face, the axial displacements are asymmetric due to the constraints produced by the tunnel face (Fig. 4).

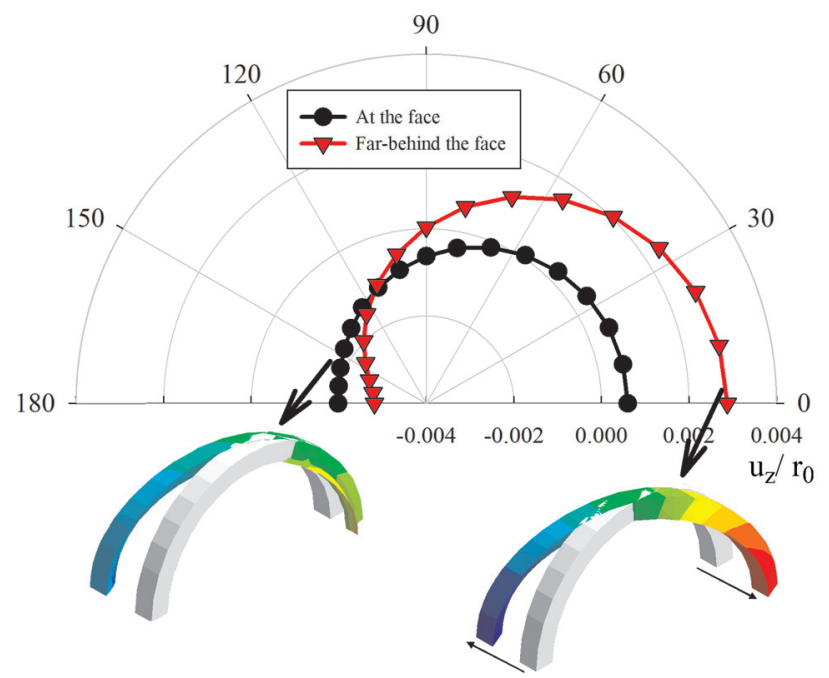

Figure 9 - Normalized axial displacements with respect to the tunnel radius along the tunnel perimeter for Case 1, complete stress field. Unsupported tunnel. The colors of the deformed tunnel cross-section are associated with the magnitude of the axial displacements and are shown to help with the visualization (the colors legend is not included for clarity, but the magnitude of the displacements is given in the plot). 
For Case 2, where the far-field axial shear stress is neglected, no anti-symmetric axial displacements are induced and so, no asymmetric radial deformations occur near the face.

If a liner is installed near the face, the asymmetric radial deformations may affect the stresses in the support. To investigate the influence of the far-field axial shear stress on supported tunnels in a horizontally structured rock masses, the two cases previously discussed are analyzed again, but with a liner placed close to the face (Fig. 2). Figure 10 shows the normalized radial displacements with the normalized distance from the face. For Case 1, complete stress field, the radial displacements at the springline are asymmetric near the face and far behind the face. For Case 2, no far-field axial shear, the radial displacements at the springline are always symmetric. Consistent with the findings from the unsupported tunnel, the asymmetric deformations are caused by the anti-symmetric axial displacements induced by the far-field axial shear stress.

Figure 11 shows the normalized radial stresses at the tunnel perimeter, with respect to the vertical stress, with the normalized distance from the face. For Case 1, complete stress field, on the right-hand side of the springline, the radial stresses increase at the face and abruptly decrease behind the face; then, they slightly increase with the distance from the face until they are constant. On the left-hand side of the springline, the radial stresses decrease ahead of the face as the distance from the face decreases and then, behind the face, they increase with distance until they are constant. The radial stresses on the right are larger than on the left springline, which is consistent with the asymmetric deformations near the face. Note that there is a translation of
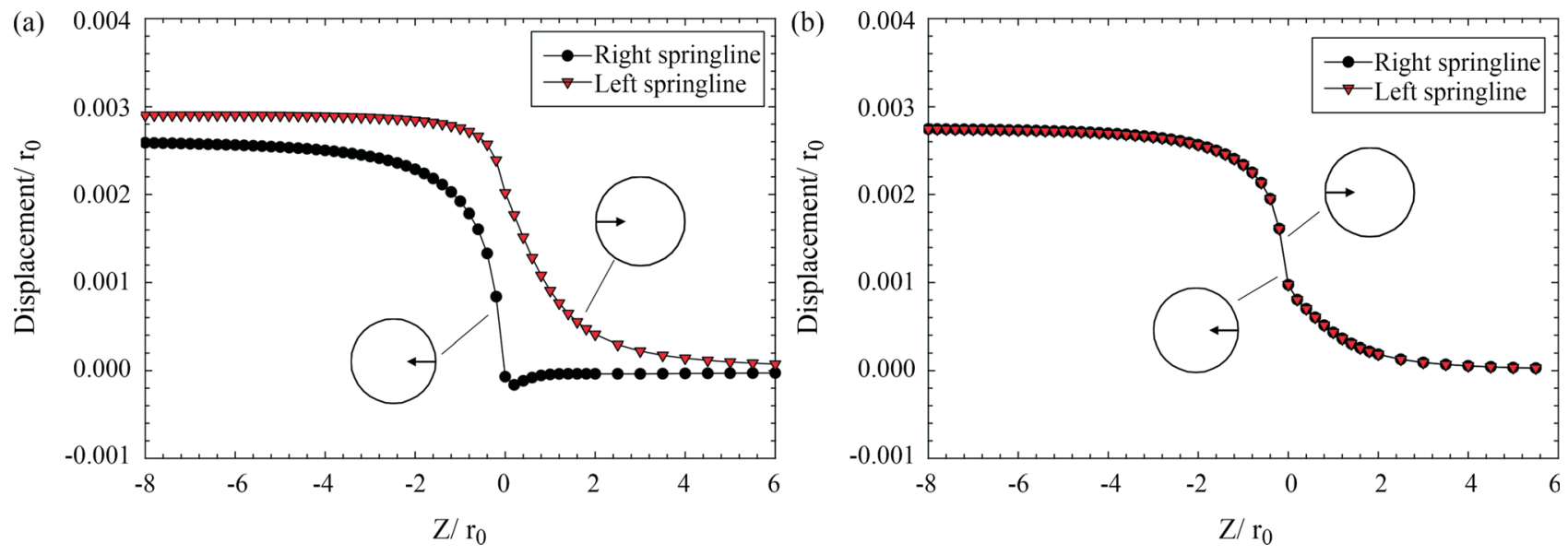

Figure 10 - Radial displacements $v$ s. distance from the face (both normalized with respect to the tunnel radius), for supported tunnel. (a) Case 1, complete stress field and, (b) Case 2, no far-field axial shear. $\mathrm{Z}$ is the distance from the face of the tunnel (Fig. 2); $\mathrm{r}_{0}$, the tunnel radius, is $5 \mathrm{~m}$. The circles represent the tunnel cross section and the arrows indicate the direction and location of the displacements plotted.
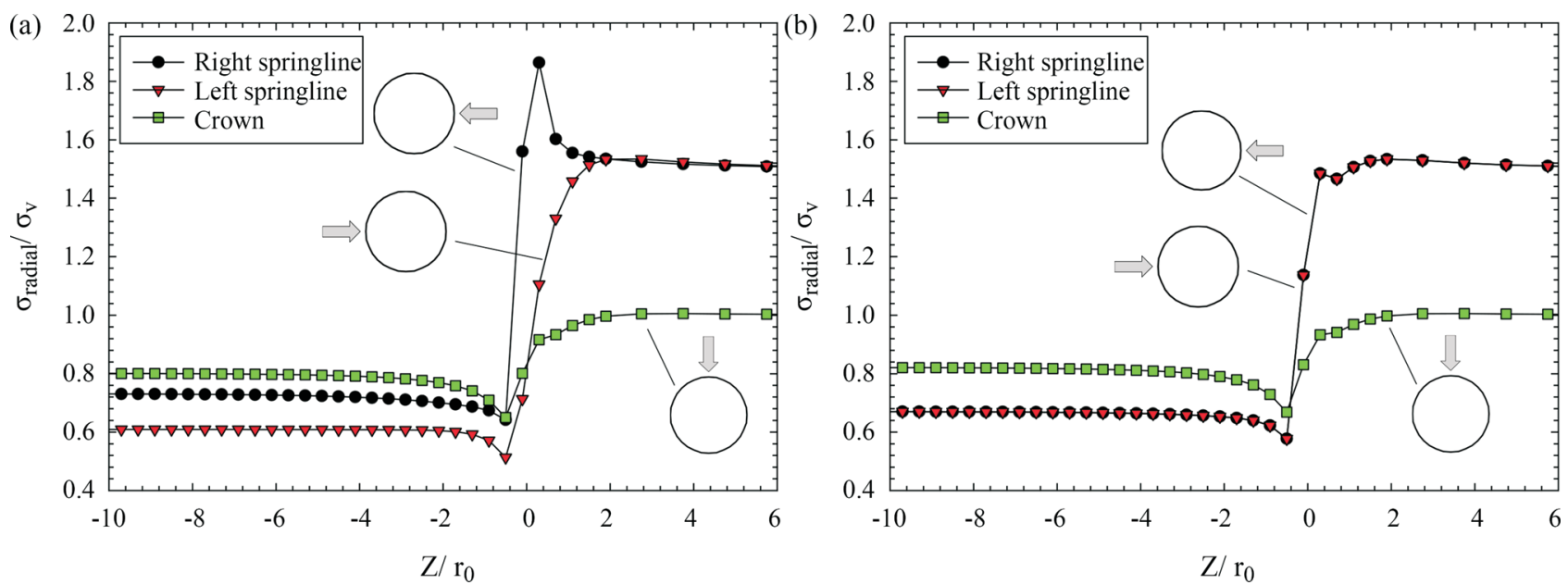

Figure 11 - Normalized radial stresses with respect to the far-field vertical stress $v s$. the normalized distance from the face with respect to the tunnel radius, for supported tunnel. (a) Case 1, complete stress field; (b) Case 2, no far-field axial sher stress. $\mathrm{Z}$ is the distance from the face of the tunnel (Fig. 2); $r_{0}$, the tunnel radius, is $5 \mathrm{~m}$. The circles represent the tunnel cross section and the arrows indicate the direction and location of the radial stresses plotted. 
the tunnel cross section towards the right (Fig. 4.a.1), which compresses the right springline and unloads the left. For Case 2, the radial stresses are the same (i.e. both abruptly decrease at the face and slightly increase behind the face until they are constant far-behind the face). It is interesting to note that the radial stresses at the crown are similar in both cases. At the crown, the radial stresses decrease ahead of the face and increase behind the face until they reach a constant value. Note that, behind the face, the radial stresses at the crown are larger than at the springline. Figure 12 shows the internal forces in the liner, normalized with respect to the vertical stress and the tunnel radius. The internal forces (i.e. thrust forces and bending moments) are symmetric for Case 2 (no far-field axial shear) and asymmetric for Case 1 (complete stress field), where they are larger on the right than on the left. This observation is consistent with the asymmetric radial displacements that occur at the tunnel perimeter. Note also that Case 1 produces the largest internal forces.

\section{Tunnel in Vertically-Structured Rock Mass}

In this analysis, the tunnel is inclined $45^{\circ}$ with the strike of the rock structure and with the geostatic principal horizontal stresses, as shown in Fig. 13. The figure also shows the boundary conditions of the FEM model, which are analogous to those in Fig. 2. Three cases are investigated: (1) major horizontal stress $\left(\sigma_{H}\right)$ perpendicular to the strike; (2) no far-field axial shear stress; and (3) major horizontal stress $\left(\sigma_{H}\right)$ perpendicular to the strike. The far-field horizontal and axial stress are the same in all three scenarios (i.e. $\sigma_{x x: f f}=\sigma_{z z \text { z.ff }}=7.5 \mathrm{MPa}$ ). When $\sigma_{H}$ is perpendicular to the strike (Case 1), the far-field axial shear stress $\left(\tau_{x z f f}\right)$ is

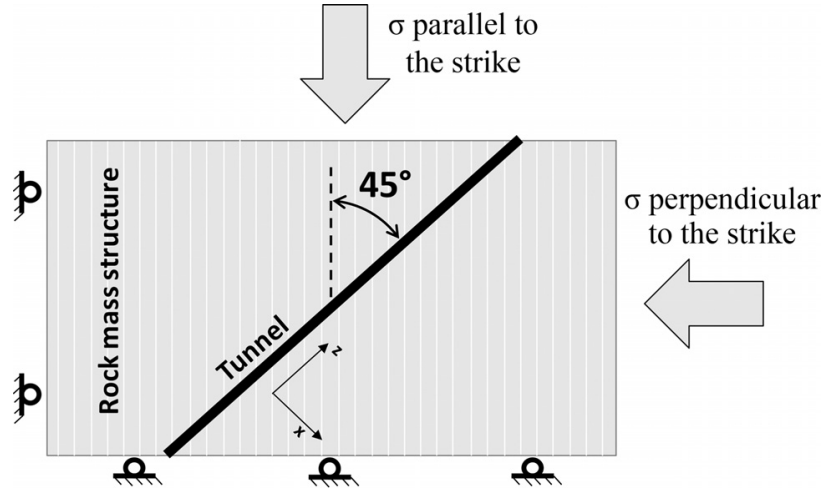

Figure 13 - Plan view of the tunnel misaligned with the vertically structured rock mass and boundary conditions.

2.5 $\mathrm{MPa}$, and when parallel to the strike (Case 3), $\tau_{x z \text { fff }}=-2.5 \mathrm{MPa}$. Case 2 assumes $\tau_{x z \text { z ff }}=0$.

The axial displacements at the tunnel perimeter, normalized with respect to the tunnel radius, are presented in Fig. 14, for an unsupported tunnel. In all cases, axial displacements are induced far behind the face. The axial displacements are asymmetric at the face and anti-symmetric far-behind the face. The axis of anti-symmetry far-behind the face is the vertical axis in all three cases, so the maximum axial displacements are at the springline and there are no axial displacements at the crown or invert. This is because of the presence of the far-field axial shear stress and because of the tunnel misalignment with the rock mass structure. It is interesting to note that the axial displacements for Case 2, no far-field shear, are larger than for Case $3, \sigma_{H}$ parallel to the strike, but smaller than for Case $1, \sigma_{H}$ perpendicular to the strike. The reason for this is that, when $\sigma_{H}$ is perpendicular to the strike, the axial distortions produced by the far-field axial shear stress and by the rock (a)

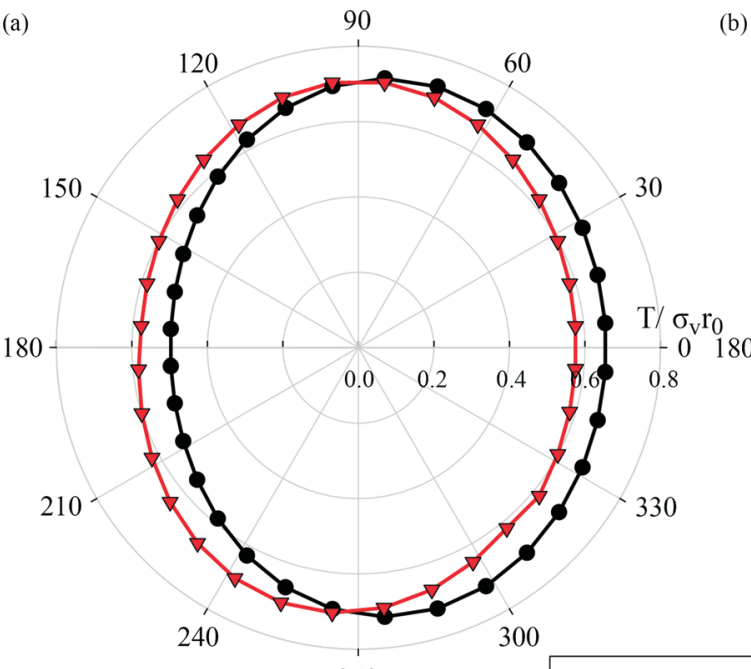

(b)

90

150

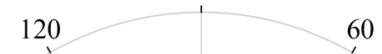

0

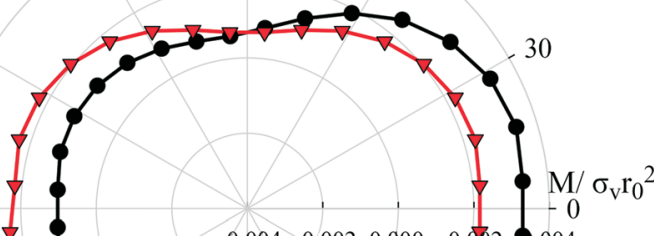

210
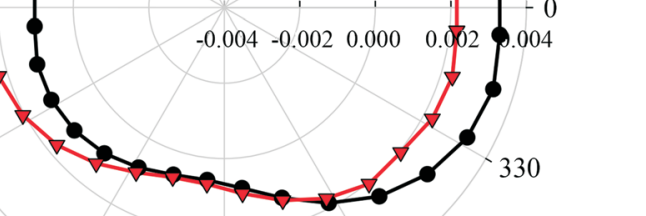

$\longrightarrow \Psi=45^{\circ}$, complete stress field
$\rightarrow-$ No far-field axial shear stress

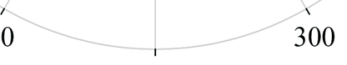

270 300

Figure 12 - Normalized internal forces with respect to the vertical stress and tunnel radius. (a) Thrust (b) Bending moment. 

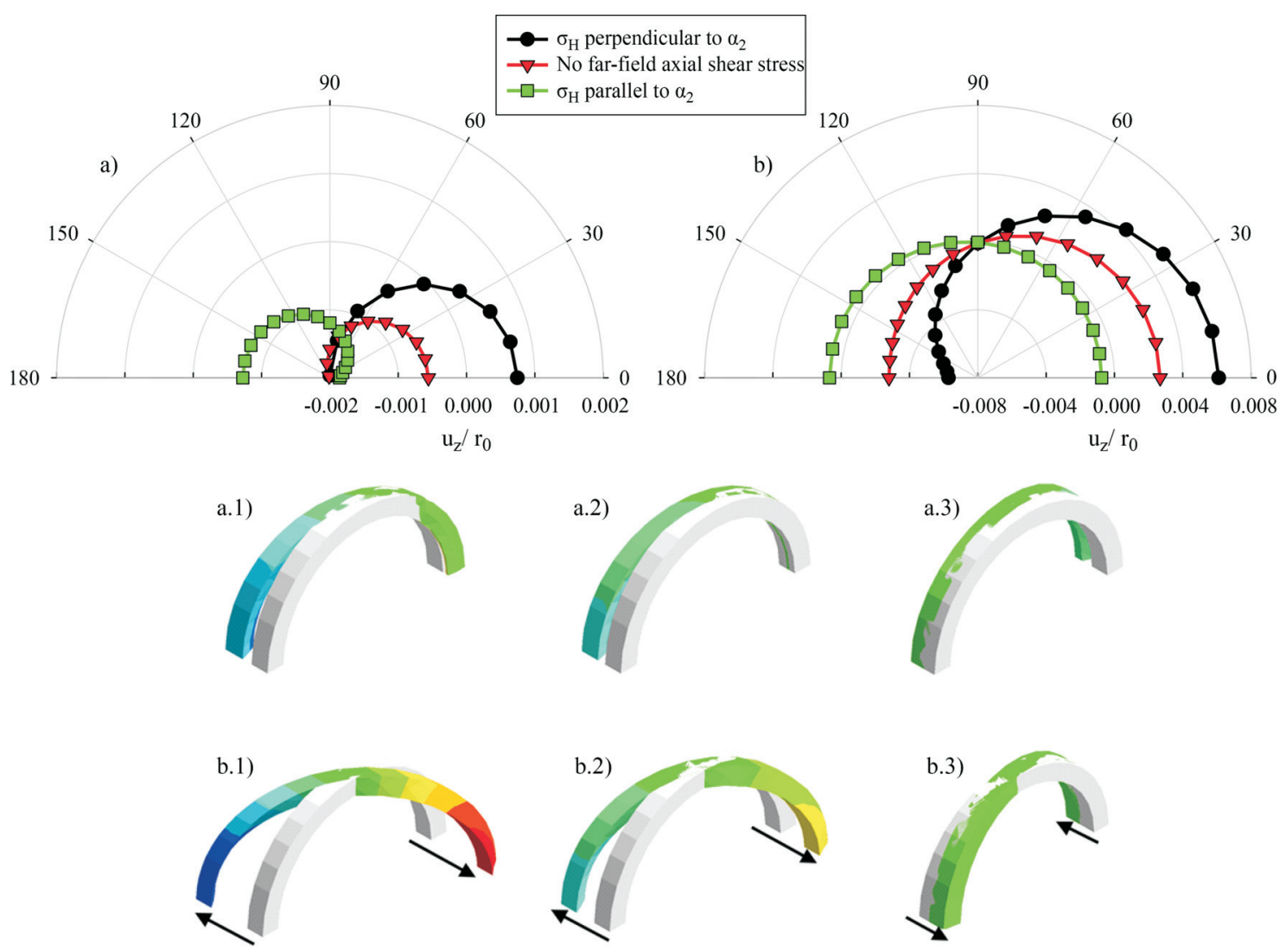

Figure 14 - Normalized axial displacements of the tunnel: (a) at the face; (b) far-behind the face. The colors of the axially deformed tunnel cross-sections are associated with the magnitude of the axial displacements and are used for visualization purposes (the colors legend is not included for clarity, but the magnitude of the displacements is given in the plot).

mass anisotropy complement each other, while when $\sigma_{H}$ is parallel to the strike, they have opposite effects.

Figure 15 shows the normalized horizontal and vertical tunnel displacements with the normalized distance from the face of the tunnel. The displacements of Case 1 with horizontally structured rock mass are plotted for compari-

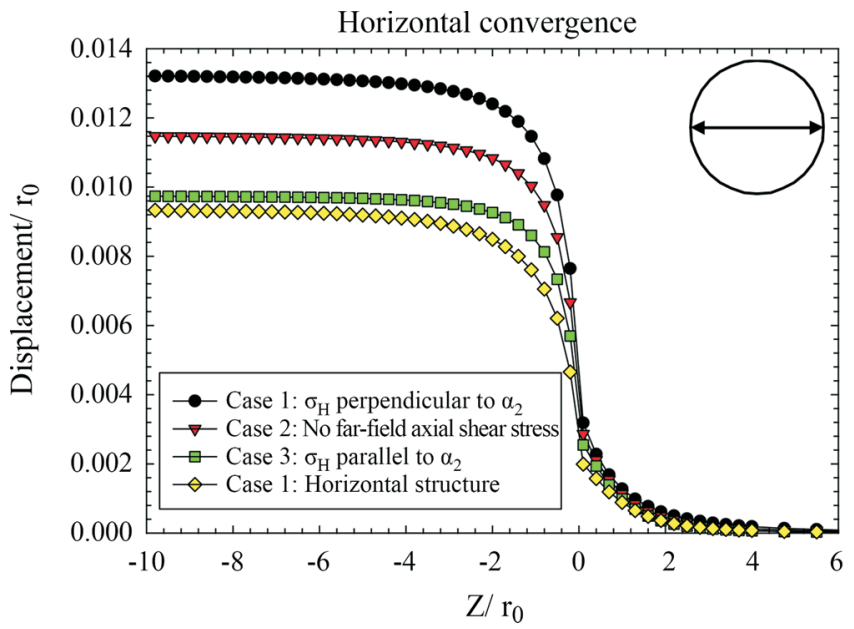

son. The vertical displacements are similar in all three cases with vertically structured rock mass and are smaller than those with horizontally structured rock mass. The reason for this is because the rock stiffness in the vertical direction is the largest for vertically structured rock mass and the smallest for horizontally structured rock mass. For verti-

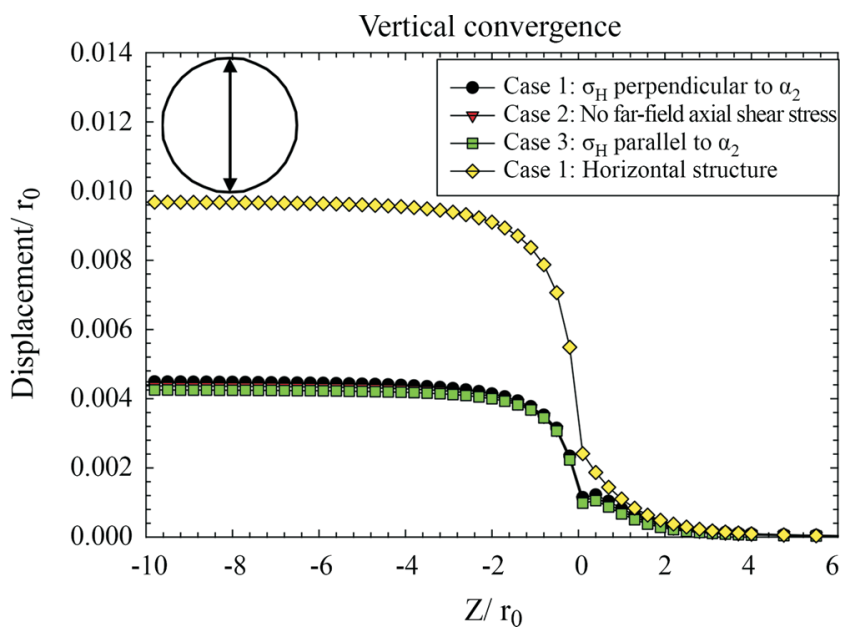

Figure 15 - Horizontal and vertical tunnel convergence $v s$. distance from the face (both normalized with respect to the tunnel radius), for unsupported tunnel. $\mathrm{Z}$ is the distance from the face of the tunnel (Fig. 2); $\mathrm{r}_{0}$, the tunnel radius, is $5 \mathrm{~m}$. The circles represent the tunnel cross section and the arrows indicate the direction and location of the displacements plotted. 
cally structured rock mass, the horizontal displacements are larger for Case $1\left(\sigma_{H}\right.$ perpendicular to the strike) and smaller for Case 3 ( $\sigma_{H}$ parallel to the strike). This is due to the compliance matrix of the transversely anisotropic elastic model, which is fully populated when the tunnel is misaligned with one of the principal axes of material anisotropy. Thus, in-plane and out-of-plane stresses and deformations are coupled. As a consequence, radial displacements are affected by the far-field axial shear stresses. Note that when the tunnel is aligned with one of the principal axes of the material anisotropy, in-plane and out-of-plane deformations are decoupled. As a consequence, the farfield axial shear stress has no influence on the radial displacements far-behind the face (see e.g. Figs. 4 and 5 for horizontally-structured rock mass). The horizontal convergence for Case 1 with horizontally structured rock mass is smaller than with vertically structured rock mass, because the rock mass stiffness is the largest in the horizontal direction than when the rock mass structure is horizontal.

Figure 16 shows the normalized radial displacements and the deformed tunnel cross-section for the cases with vertically structured rock mass and for Case 1 , with horizontally structured rock mass, which is included for comparison. At the face of the tunnel, the radial displacements are always asymmetric, but they are symmetric far-behind the face. As explained before, the asymmetric deformations near the face occur because the anti-symmetric axial displacements are constrained by the face of the tunnel. Note that the asymmetric deformations at the face and the symmetric deformations far-behind the face are larger when $\sigma_{H}$ is perpendicular to the strike (Case 1) and smaller when $\sigma_{H}$ is parallel to the strike (Case 3). At the face, a horizontal translation of the tunnel cross section occurs for all cases. The translation is towards the right for Case $1\left(\sigma_{H}\right.$ perpen-
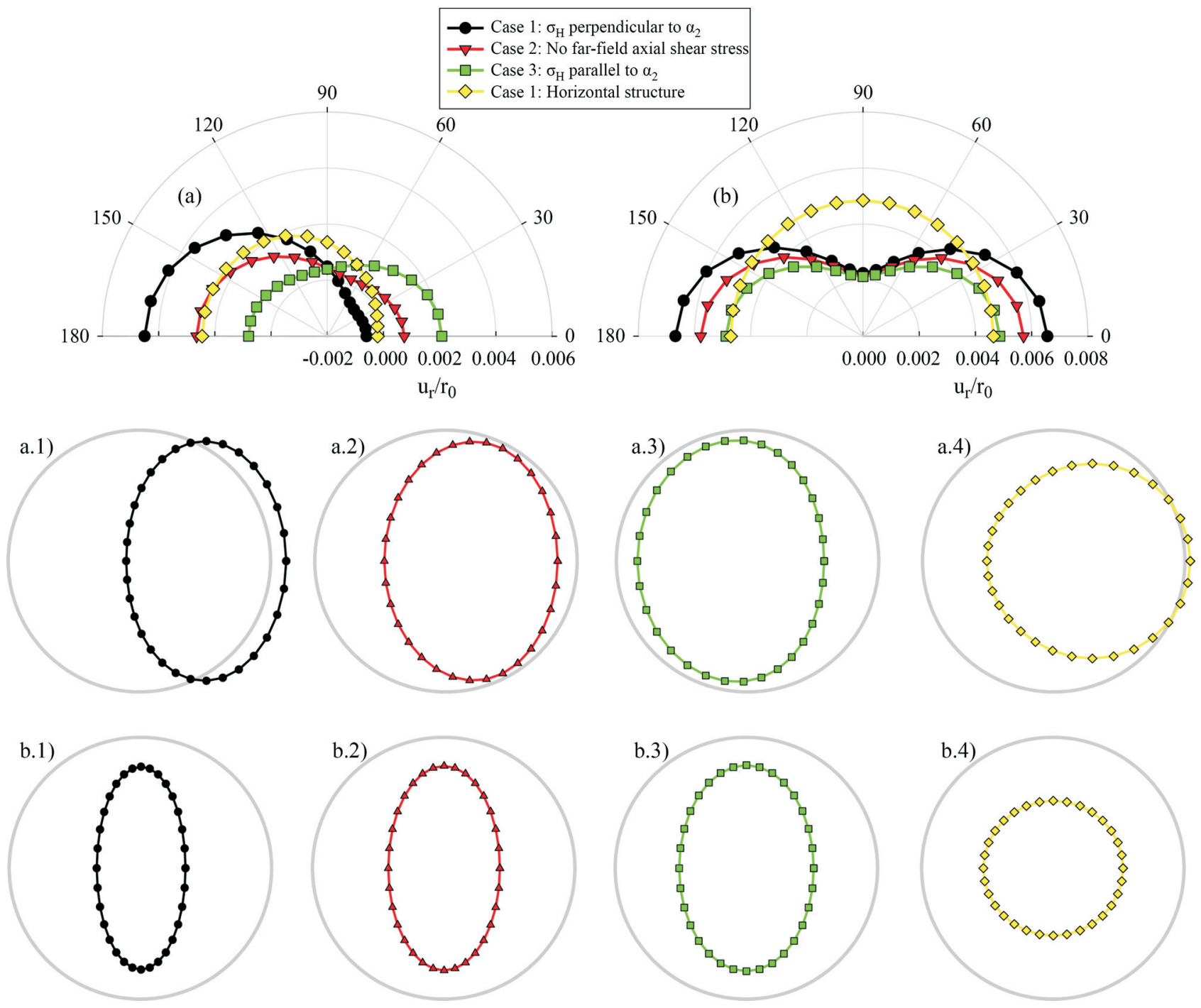

Figure 16 - Normalized radial displacements at the tunnel perimeter with respect to the tunnel radius and deformed tunnel cross-section, for unsupported tunnel. (a) at the face; (b) far-behind the face. Deformations are magnified 200 times at the face and 100 times far-behind the face. 
dicular to the strike, Fig. 16.a.1), Case 2 (no far-field axial shear stress, Fig. 16.a.2) and for Case 1 with horizontally structured rock mass (Fig. 16.a.4), but it is towards the left for Case $3\left(\sigma_{H}\right.$ parallel to the strike, Fig. 16.a.3). As one can see in Fig. 16, the deformed tunnel cross-section has a pronounced ellipsoidal shape far-behind the face when the rock structure is vertical (Cases 1 to 3 ). This is the result of
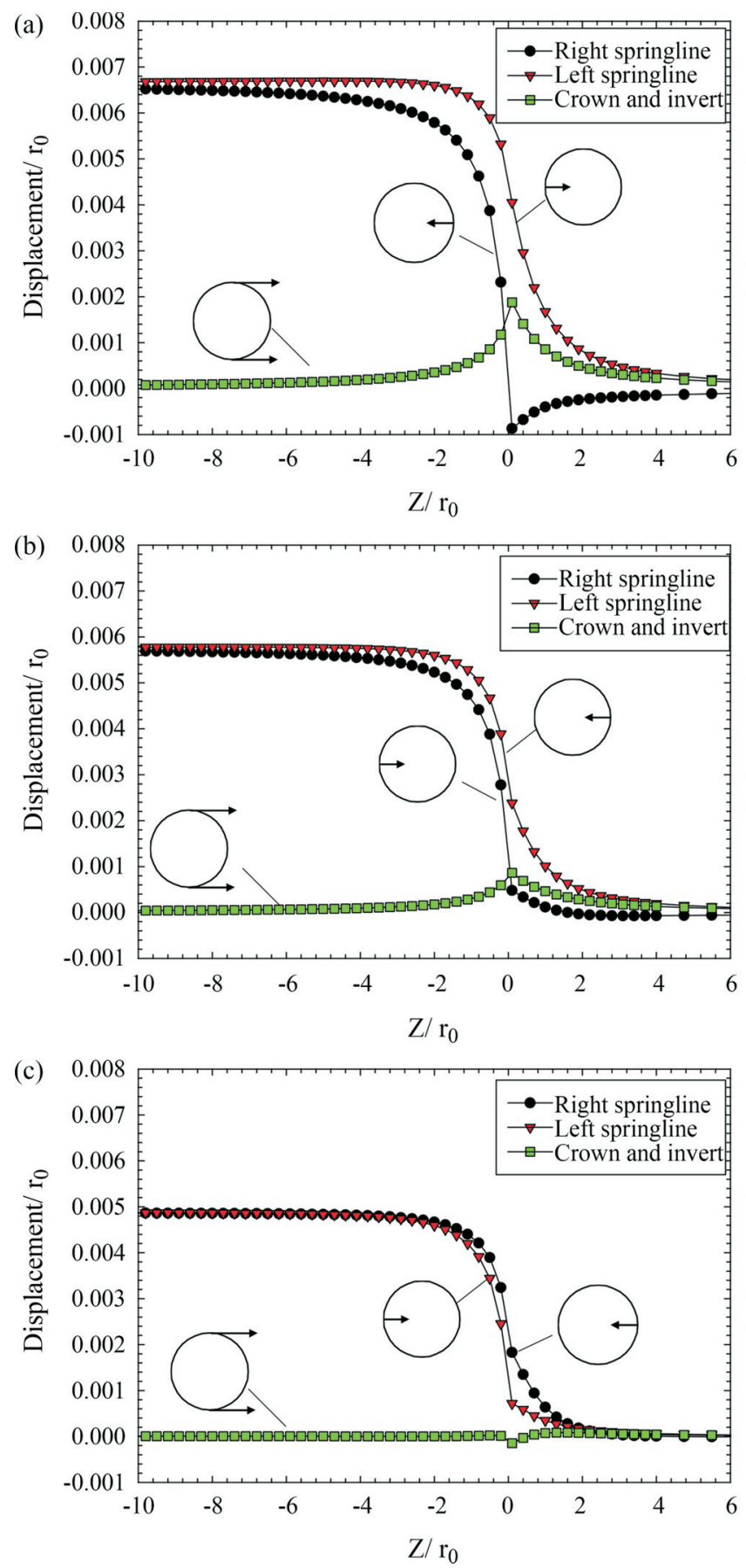

a far-field horizontal stress larger than vertical, and the fact that the larger horizontal stress is applied in the direction of the smaller stiffness of the rock. The opposite happens in the horizontally structured rock mass, as discussed in the previous section.

Figure 17 shows the normalized radial displacements at the springline and the horizontal translation of the tunnel
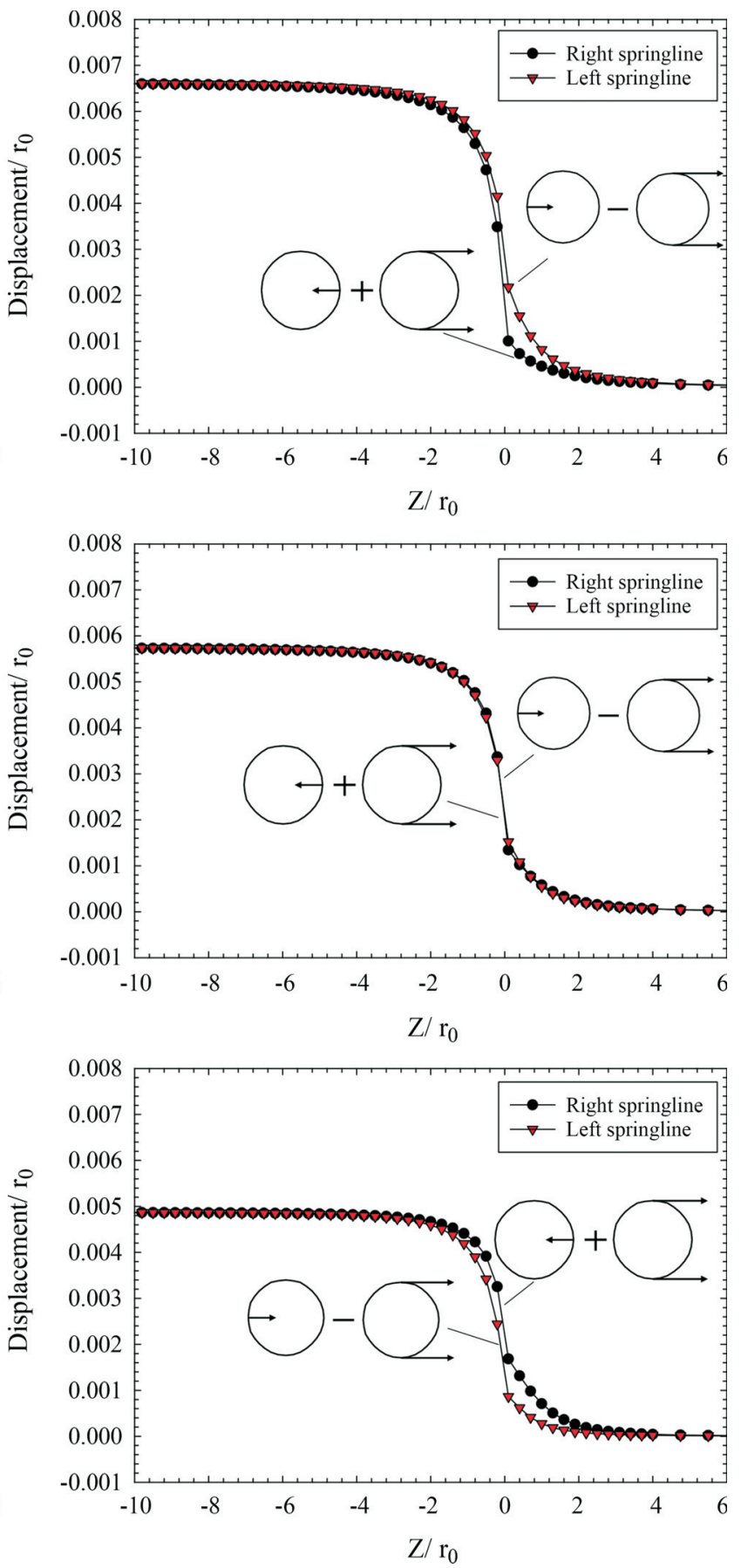

Figure 17 - Normalized radial and horizontal translation of the tunnel cross section with respect to the tunnel radius vs. the normalized distance from the face with respect to the tunnel radius, for unsupported tunnel. (a) Case 1, $\sigma_{H}$ perpendicular to the strike; (b) Case 2, no far-field axial shear stress and; (c) Case $3 \sigma_{H}$ parallel to the strike. $Z$ is the distance from the face of the tunnel (Fig. 2); $r_{0}$, the tunnel radius, is $5 \mathrm{~m}$. The circles represent the tunnel cross section and the arrows indicate the direction and location of the displacements plotted. 
cross section with the normalized distance from the face of the tunnel. The radial displacements on the left and right at the springline are different near the face but are the same far-behind the face. The horizontal translation of the tunnel cross section occurs near the face in all three scenarios; it is maximum at the face and reduces to zero far behind the face. Figure 17 also shows the "corrected" radial displacements, which are the radial displacements without the translation, as indicated in the graphs. For Case 2, no far-field axial shear stress, the corrected radial displacements are the same (within numerical approximation) on both sides of the springline. For Cases 1 and 3, where the far-field axial shear stress is not zero, the corrected radial displacements near the face are asymmetric. Thus, the horizontal translation observed in Case 2, no far-field axial shear, is in reality a horizontal rigid body displacement of the tunnel cross section, while in Cases 1 and 3, where the far-field axial shear stress is present, the deformations are more complex. The combination of rock anisotropy and far-field axial shear produces a response of the rock around the tunnel quite different (and more complex) than when the rock is isotropic. Indeed, in isotropic elastic ground, Vitali et al. (2019b) observed that the asymmetric radial deformations near the face due to a far-field axial shear stress could be decomposed into a rigid body displacement of the tunnel cross-section and anti-symmetric radial displacements, which is not always the case in anisotropic rock.

Figure 18 shows the stress paths at the springline, normalized with respect to the vertical stress. The labels $(1,2$ and 3) shown in Fig. 18 refer to positions far-ahead of the face (1), at the face (2), and far-behind the face (3), as indicated in Fig. 2. The stresses are extracted at a distance of $0.1 \mathrm{r}_{0}$ from the tunnel perimeter, to avoid the mathematical singularity at the corner formed between the tunnel face and the excavation. As a consequence of the asymmetric deformations near the face, the stress paths are asymmetric near the face as well. For Case $1, \sigma_{H}$ perpendicular to the strike, the rock on the right-hand side of the springline takes load ahead of the face, the stresses increase near the face, and then they decrease behind the face. On the left, the stresses decrease ahead of the face and increase behind the face. Note that the stresses on the right and left springlines far-behind the face are the same. The stress paths are consistent with a horizontal translation of the tunnel cross section towards the right, which compresses the rock at the springline, to the right, and unloads to the left. The opposite is observed for Case $3, \sigma_{H}$ parallel to the strike. On the right, there is unloading ahead of the face and loading behind the face; on the left springline, there is loading ahead of the face and unloading behind. Note that the tunnel translation in Case 3 is towards the left. For Case 2, no far-field axial shear stress, both sides of the springline follow the same stress path. The stresses near the face are larger at the right springline, which is consistent with the observed horizontal translation towards the right. It is interesting to note that the unloading stress path ahead of the face is only observed when the far-field axial shear stress is present. Figure 19 shows the normalized stress paths at the crown with respect to the vertical stress, for the three cases with vertically structured rock mass, and for Case 1, with horizontally structured rock mass, which is included for comparison. As one can see, all the stresses increase near the face. The shear stresses are smaller for Case 2, no far-field axial shear stress, than for the other cases. Far-behind the face, the stress state for Case $1, \sigma_{H}$ perpendicular to the strike, and Case $3, \sigma_{H}$ parallel to the strike, are the same and slightly different than for Case 1, with horizontally structured rock mass. This finding suggests that the orientation of the rock structure with respect to the tunnel strongly affects the ground deformations around the tunnel, particularly near
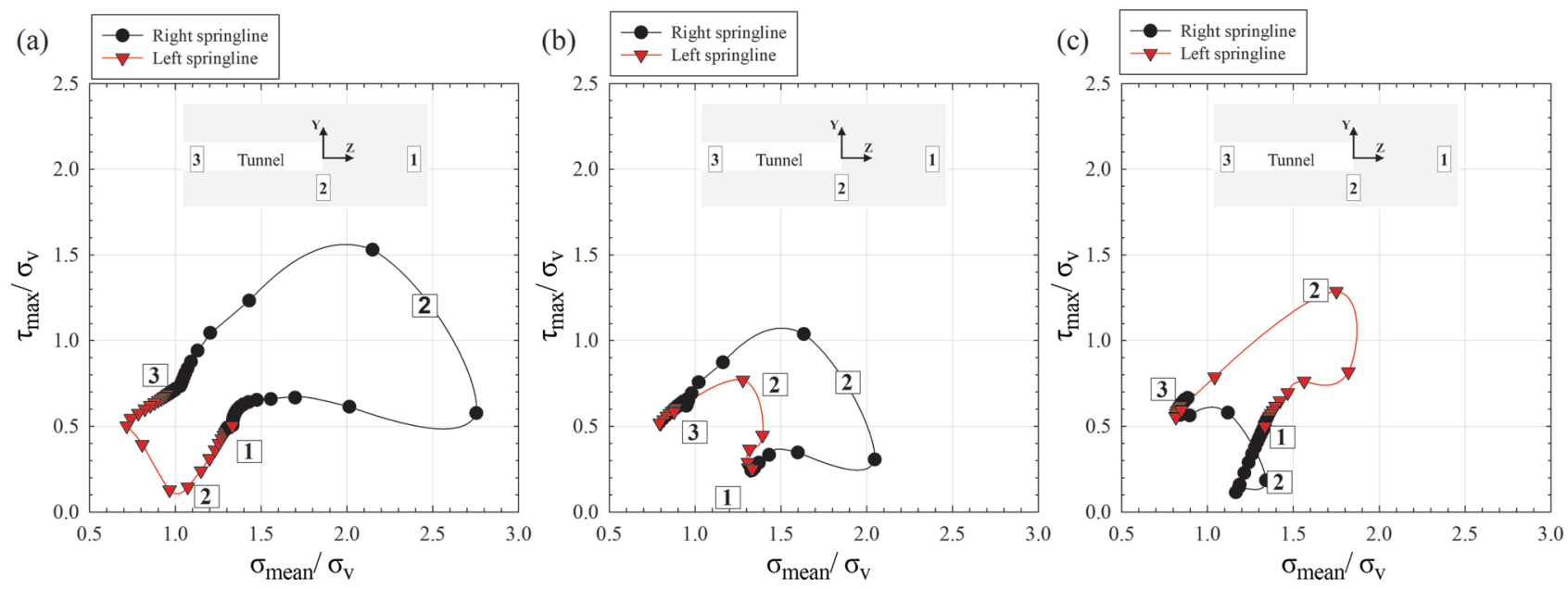

Figure 18 - Normalized stress paths with respect to the vertical stress for unsupported tunnel. (a) Case 1: $\sigma_{H}$ perpendicular to the strike; (b) Case 2, no far-field axial shear stress; and (c) Case 3, $\sigma_{H}$ parallel to the strike. Position (1) represents a point far ahead of the face of the tunnel; (2), at the face (i.e. $\mathrm{Z}=0$ ); and (3), far-behind the face. 


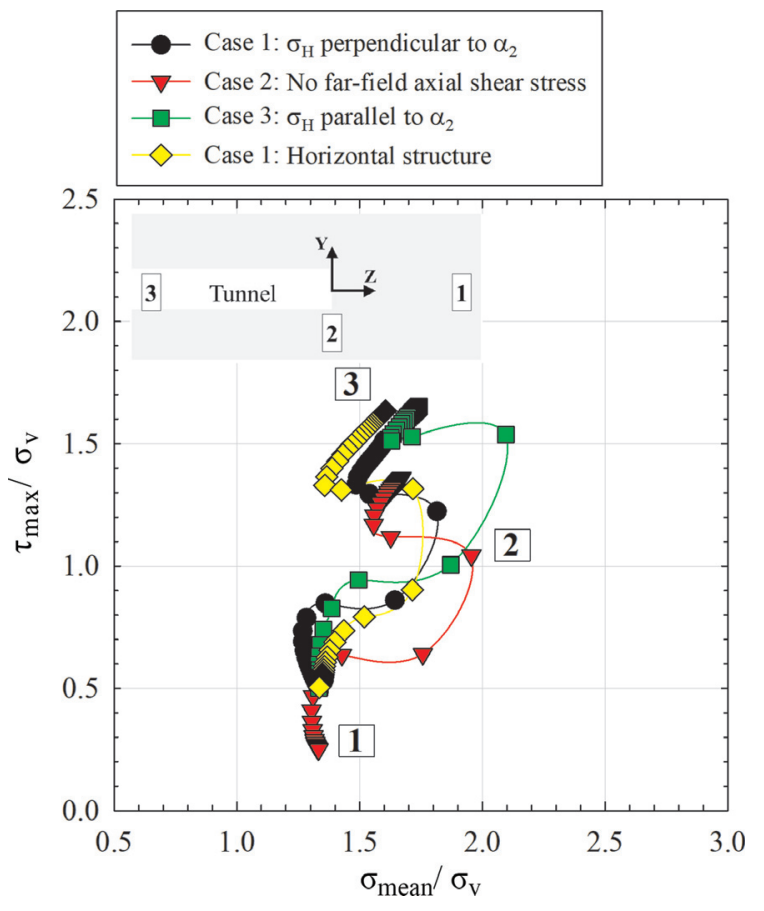

Figure 19 - Stress paths at the crown. Position (1) represents a point far ahead of the face of the tunnel; (2), at the face (i.e. $\mathrm{Z}=0$ ); and (3), far-behind the face.

the face of the tunnel, but has limited influence on the stresses around the tunnel far-behind the face.

The asymmetric deformations found near the face may affect the liner, if the tunnel is supported. This is investigated by running three new cases, all analogous to the previous cases discussed, but with a liner placed close to the face (Fig. 2). The results are presented in Figs. 20 and 21. Figure 20 shows the normalized radial stresses with the normalized distance from the tunnel face. As a consequence of the asymmetric deformations near the face, the radial stresses at the tunnel perimeter are asymmetric near and far-behind the face. The largest stress asymmetries oc- cur for Case 1, when $\sigma_{H}$ is perpendicular to the strike, and the smallest for Case 2, no far-field axial shear stress. The radial stresses are larger at the right springline when $\sigma_{H}$ is perpendicular to the strike and when there is no far-field axial shear stress, but are larger at the left when $\sigma_{H}$ is parallel to the strike. This is consistent with the direction of the tunnel cross section translation observed. The radial stresses at the crown are similar for the three cases and are larger than the stresses at the springline, given that the horizontal stress is larger than the vertical (i.e. stress concentrations are larger at the crown). Figure 21 shows the internal forces of the liner normalized with respect to the vertical stress and the tunnel radius. The internal forces are always asymmetric. The thrust is larger at the crown and at the invert and is smaller at the springline, while the bending moments are larger at the springline. The internal forces are larger for Case 1, when $\sigma_{H}$ is perpendicular to the strike and are smaller for Case 3, when $\sigma_{H}$ is parallel to the strike. This is expected because the radial deformations are larger for Case 1 and smaller for Case 3, as shown in Figs. 15, 16 and 17. It is interesting to note that the internal forces for the cases with far-field axial shear stress (Cases 1 and 3) are more asymmetric than the case with no far-field axial shear stress (Case 2).

\section{Conclusions}

The effects of the tunnel misalignment with the geostatic principal stress directions in anisotropic rock masses are investigated in this paper. Far-field axial shear stresses are present when the tunnel is not aligned with the geostatic principal stress directions. Anti-symmetric axial displacements and axial shear stresses are induced around the tunnel due to the tunnel misalignment with the geostatic principal stress directions and with the principal material directions. Near the face, axial displacements are constrained by the face of the tunnel; as a consequence, asymmetric radial deformations occur near the face. 3D FEM
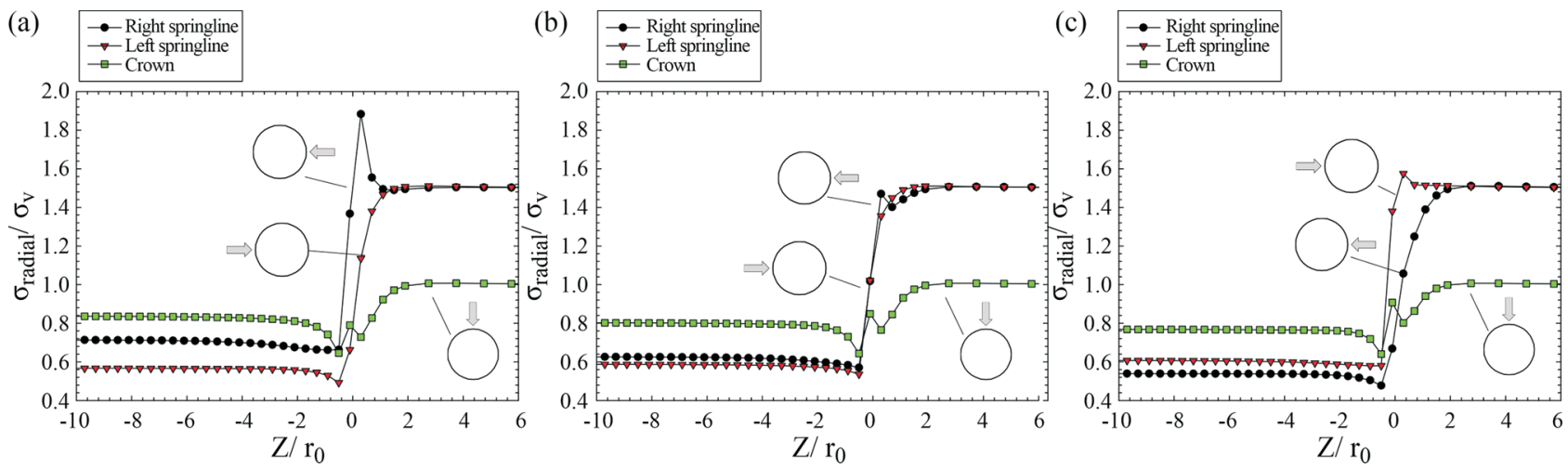

Figure 20 - Normalized radial stresses with respect to the vertical stress $v s$. the normalized distance from the face with respect to the tunnel radius, for supported tunnel. (a) Case 1, $\sigma_{H}$ perpendicular to the strike; (b) Case 2, no far-field axial shear stress; and (c) Case 3, $\sigma_{H}$ parallel to the strike. $\mathrm{Z}$ is the distance from the face of the tunnel (Fig. 2); $r_{0}$, the tunnel radius, is $5 \mathrm{~m}$. The circles represent the tunnel cross section and the arrows indicate the direction and location of the radial stresses plotted. 


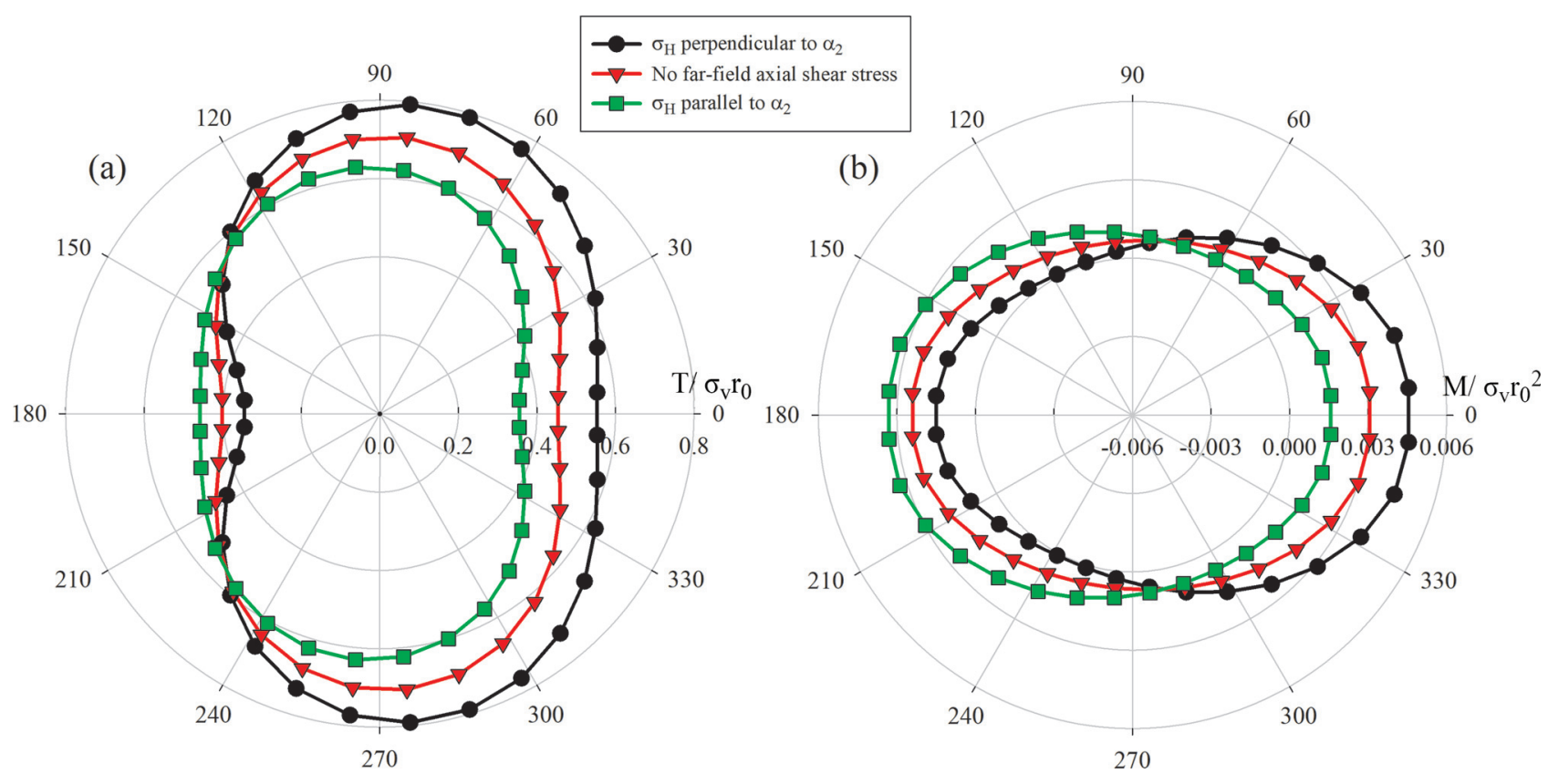

Figure 21 - Normalized internal forces with the vertical stress and tunnel radius. (a) Thrust; (b) Bending moment.

simulations of a tunnel at $45^{\circ}$ with the horizontal principal stresses have been performed, with an anisotropic geostatic stress field. Two scenarios have been investigated: a horizontal tunnel in rock mass with horizontal structure, and in a rock mass with a vertical structure. In both scenarios, the rock response is approximated through a transversely anisotropic elastic model. Both unsupported and supported tunnels are considered.

For the scenario with the horizontally-structured rock mass, the tunnel is always aligned with the rock mass structure. Asymmetric radial deformations near the face of the tunnel occur when a far-field axial shear stress is present. Far-behind the face, for the unsupported tunnel, the radial displacements are symmetric, which indicates that the farfield axial shear stress does not affect the radial displacements far-behind the face. The reason is that, when the tunnel is aligned with one of the principal material directions, in-plane and out-of-plane deformations are decoupled. For supported tunnels, the asymmetric deformations near the face affect the liner response. Far behind the face, asymmetric radial displacements and stresses are present, so the internal forces in the liner are asymmetric.

For the scenario where the rock mass structure is vertical and the tunnel axis makes an angle of $45^{\circ}$ with the strike or the rock structure, axial displacements and axial shear stresses are induced around the tunnel. Three scenarios are being investigated: major horizontal stress parallel to the strike direction, major horizontal stress perpendicular to the tunnel direction and no far-field axial shear stress. Far-behind the face, the induced axial displacements are always anti-symmetric with respect to the vertical axis. The largest axial displacements occur when $\sigma_{H}$ is perpendicular to the strike and the smallest when $\sigma_{H}$ is parallel to the strike. This is because, when $\sigma_{H}$ is perpendicular to the strike, the axial distortion of the tunnel cross section produced by the far-field axial shear stress and by the rock mass structure complement each other. The opposite happens when $\sigma_{H}$ is parallel to the strike. Near the face, asymmetric deformations are induced. The asymmetric radial deformations near the face are larger when $\sigma_{H}$ is perpendicular to the strike and smaller when $\sigma_{H}$ is parallel. The same is true far-behind the face of the tunnel. In other words, the far-field axial shear stress affects the radial displacements far-behind the face when the tunnel is misaligned with the principal directions of material anisotropy. For supported tunnels, the radial stresses at the tunnel perimeter are asymmetric near the face and far-behind the face. Thus, the internal forces in the tunnel liner are asymmetric. The largest internal forces occur when $\sigma_{H}$ is perpendicular to the strike and the smallest when $\sigma_{H}$ is parallel to the strike.

The ground deformations far-behind the tunnel face are heavily affected by the orientation of the rock mass structure with the tunnel. For the horizontally structured rock mass, the deformed tunnel cross section far-behind the face has a slightly ellipsoidal shape (i.e. the radial displacements at the springline are similar to those at the crown and invert). In contrast, for vertically-structured rock mass, the deformed tunnel cross section has a pronounced ellipsoidal shape, where the radial displacements at the springline are substantially larger than at the crown and invert. For this specific case, the far-field horizontal stress is larger than the vertical. Thus, for horizontally-structured rock mass, the largest stresses are aligned with the stiffest material direction (i.e. parallel to the rock structure) and the smallest 
stresses are aligned with the softest material direction (i.e. perpendicular to the strike). The opposite occurs for vertically-structured rock mass. The rock stresses near the tunnel perimeter for horizontally- and vertically-structured rock mass are similar far-behind the face, which seems to suggest that rock anisotropy has a modest influence on the stresses far behind the face of the tunnel.

The results presented in this paper provide insight into the complex behavior of tunnels in anisotropic rock masses, and highlight the importance of considering the tunnel misalignment with the geostatic principal stress directions and with the rock mass structural planes. Also, the results show the importance of the orientation of the geostatic principal stress directions with respect to the principal directions of material anisotropy.

\section{Acknowledgments}

The research is being partially supported by the research funding agency of the Brazilian government $\mathrm{CNPq}$ ("Conselho Nacional de Desenvolvimento Científico e Tecnológico"). The authors acknowledge the support from CNPq and from Midas company, which kindly provided the license of Midas GTX NX software, used in the present work.

\section{References}

Armand, G.; Noiret, A.; Zghondi, J. \& Seyedi, D.M. (2013). Short- and long-term behaviors of drifts in the Callovo-Oxfordian claystone at the Meuse/Haute-Marne Underground Research Laboratory. Journal of Rock Mechanics and Geotechnical Engineering, 5(3):221230.

Brady, B.H.G. \& Brown, E.T. (2006). Rock Mechanics for Underground Mining. $3^{\text {rd }}$ ed. Springer, New York, $628 \mathrm{p}$.

Brown, E.T. \& Hoek, E. (1978). Trends in relationships between measured in-situ stresses and depth. Int. J. Rock Mech. Min. Sci., 15(4):211-215.

Button, E.; Leitner, R.; Poetsch, M. \& Schubert, W. (2006). Spatial relationships between discontinuity orientation and system behavior in underground excavations. Proc. ARMA 41st U.S. Symposium on Rock Mechanics. ARMA/USRMS 06-957.

Evans, K.F.; Engelder, T. \& Plumb R.A. (1989). Appalachian Stress study .1. a detailed description of in-situ stress variations in devonian shales of the appalachian plateau. J. Geophys. Res. Earth Planets, 94:7129-7154.

Fortsakis, P.; Nikas, K.; Marinos, K.V. \& Marinos, P. (2012). Anisotropic behaviour of stratified rock masses in tunnelling. Eng. Geol., 141-142:74-83.

Goodman, R.E. (1989). Introduction to Rock Mechanics. $2^{\text {nd }}$ ed. Willey, New York, $576 \mathrm{p}$.

Goricki, A.; Button, A.E.; Schubert, W.; Pötsch, M. \& Leitner, R. (2005). The influence of discontinuity orien- tation on the behaviour of tunnels. Felsbau., 23(5):1218.

Gysel, M. (1975). In-Situ stress measurements of the primary stress state in the Sonnenberg tunnel in Lucerne, Switzerland. Tectonophysics, 29:301-314.

Haimson, B.C.; Lee, M.Y. \& Song, I. (2003). Shallow hydraulic fracturing measurements in Korea support tectonic and seismic indicators of regional stress. Int. J. Rock Mech. Min. Sci., 40(7-8):1243-1256.

Hoek, E. (2007). Practical Rock Engineering, 2007 ed. Available for download at: https://www.rocscience.com/learn-

ing/hoeks-corner/course-notes-books (last visit on March, 23 $\left.3^{\text {rd }}, 2020\right)$.

Klopcic, J. \& Logar, J. (2014). Effect of relative orientation of anisotropy planes to tunnel axis on the magnitude of tunnelling displacements. International Journal of Rock Mechanics and Mining Sciences, 71:235-248.

Lenz, G.; Kluckner, A.; Holzer, R.; Stadlmann, T.; Schachinger, T. \& Gobiet, G. (2017). Prediction of fault zones based on geological and geotechnical observations during tunnel construction. Geomechanics and Tunneling, 10(4):366-379.

Martin, C.D. (1997). Seventeenth Canadian Geotechnical Colloquium: The effect of cohesion loss and stress path on brittle rock strength. Canadian Geotechnical Journal, 34(5):698-725.

McGarr, A. \& Gay, N.C. (1978). State of Stress in the Earth's Crust. Ann. Rev. Earth Planet., Sci. 6:405-436.

Park, E.S.; Choi, B.H.; Bae, S.H. \& Jeon, S. (2014). Horizontal stresses at shallow depths in Seoul (Korea) gneissic region. Proc. EUROCK 2014, Rock Eng. Rock Mech. Struct. Rock Masses, ISRM European Regional Symposium, pp. 399-404.

Perras, M.A.; Wannenmacher, H. \& Diederichs, M.S. (2015). Underground excavation behaviour of the Queenston formation: tunnel back analysis for application to shaft damage dimension prediction. Rock Mech. Rock Eng., 48(4):1647-1671.

Schubert, W. \& Budil, A. (1995). The importance of longitudinal deformation in tunnel excavation. Proc. 8th ISRM Congress on Rock Mechanics, pp. 1411-1414.

Schubert, P.; Klopcic, J.; Stimulak, A.; Ajdic, I. \& Logar, J. (2005). Analysis of characteristic deformation patterns at the Trojane tunnel in Slovenia. Felsbau, 23(5):25-30.

Schubert, W. \& Moritz, B. (2011). State of the art in evaluation and interpretation of displacement monitoring data in tunnels. Geomechanics and Tunneling, 4(5):371380.

Souce, K.; Vavro, M.; Stas, L.; Vavro, L.; Waclawik, P.; Konicek, P.; Ptácek, J. \& Vondrovic, L. (2017) Geotechnical characterization of Bukov underground research facility. Procedia Engineering, 191:711-718. 
Tonon, F. \& Amadei, B. (2002). Effect of elastic anisotropy on tunnel wall displacements behind a tunnel face. Rock Mech. Rock Eng., 35(3):141-160.

Tonon, F. \& Amadei, B. (2003). Stresses in anisotropic rock masses: An engineering perspective building on geological knowledge. Int. J. Rock Mech. Min. Sci., 40(7-8):1099-1120.

Vitali, O.P.M.; Celestino, T.B. \& Bobet, A. (2017). 3D finite element modelling optimization for deep tunnels with material nonlinearity. Undergr. Sp., 3(2):125-139.

Vitali, O.P.M.; Celestino, T.B. \& Bobet, A. (2018). Analytical solution for tunnels not aligned with geostatic principal stress directions. Tunn. Undergr. Sp. Technol., 82:394-405.

Vitali, O.P.M.; Celestino, T.B. \& Bobet, A. (2019a). Shallow tunnel not aligned with the geostatic principal stress directions. Proc. Geo-Congress2019, GSP, 313:214222.

Vitali, O.P.M.; Celestino, T.B. \& Bobet, A. (2019b). Shallow tunnels misaligned with geostatic principal stress directions: analytical solution and 3D face effects. Tunn. Undergr. Sp. Technol., 89:268-283.

Vitali, O.P.M.; Celestino, T.B. \& Bobet, A. (2019c). Progressive failure due to tunnel misalignment with geo- static principal stresses. Proc. ISRM 14th International Congress on Rock Mechanics, pp. 2292-2299.

Vitali, O.P.M.; Celestino, T.B. \& Bobet, A. (2020). Analytical solution for a deep circular tunnel in anisotropic ground and anisotropic geostatic stresses. Manuscript under review for publication in a peer-reviewed journal.

Wileveau, Y.; Cornet, F.H.; Desroches, J. \& Blumling, P. (2007). Complete in situ stress determination in an argillite sedimentary formation. Phys. Chem. Earth, 32(8-14):866-878.

Worotnicki, G. (2013). CSIRO Triaxial Stress Measurement Cell. In: Rock testing and site characterization: principles, practice and projects: $329-394$.

Zhao, X.G.; Wang, J.; Cai, M.; Ma, L.K.; Zong, Z.H.; Wang, X.Y.; Su, R.; Chen, W.M.; Zhao, H.G.; Chen, Q.C.; An, Q.M.; Qin, X.H.; Ou, M.Y. \& Zhao, J.S. (2013). In-situ stress measurements and regional stress field assessment of the Beishan area, China. Eng. Geol., 163:26-40.

Zhao, X.G.; Wang, J.; Qin, X.H.; Cai, M.; Su, R.; He, J.G.; Zong, Z.H.; Ma, L.K.; Ji, R.L.; Zhang, M.; Zhang, S.; Yun, L.; Chen, Q.C.; Niu, L.L. \& An, Q.M. (2015). In-situ stress measurements and regional stress field assessment in the Xinjiang candidate area for China's HLW disposal. Eng. Geol., 197:42-56. 